\title{
1 Escape from the heat: Thermal stratification in a well-mixed estuary and implications for 2 fish species facing a changing climate
}

\author{
Brian Mahardja ${ }^{1 *}$, Samuel M. Bashevkin ${ }^{2}$, Catarina Pien $^{3}$, Michelle Nelson $^{3}$, Brittany E. Davis ${ }^{3}$, Rosemary \\ Hartman $^{3}$ \\ ${ }^{1}$ United States Bureau of Reclamation, 801 I Street, Suite 140, Sacramento, CA, 95814, USA \\ ${ }^{2}$ Delta Science Program, Delta Stewardship Council, 715 P Street, 15-300, Sacramento, CA, 95814, USA \\ ${ }^{3}$ California Department of Water Resources, 3500 Industrial Blvd, West Sacramento, CA, 95691, USA \\ *Corresponding author
}

\section{ORCID ID and e-mail:}

Brian Mahardja: 0000-0003-0695-3745,bmahardja@usbr.gov

Samuel M. Bashevkin: 0000-0001-7406-7089, sam.bashevkin@deltacouncil.ca.gov

Catarina Pien: 0000-0003-4427-6300, Catarina.Pien@water.ca.gov

Michelle Nelson: 0000-0002-8505-2090, Michelle.Nelson@water.ca.gov

Brittany E. Davis: 0000-0003-3752-1830, Brittany.E.Davis@water.ca.gov

Rosemary Hartman: 0000-0002-0642-183X, Rosemary.Hartman@water.ca.gov

Keywords: water temperature, stratification, endangered fish species, thermal stress, refugia, temperature refuge, delta smelt, chinook salmon, San Francisco Estuary

\section{Abstract}

Climate change may cause organisms to seek thermal refuge from rising temperatures, either by shifting their ranges or seeking microrefugia within their existing ranges. We evaluate the potential for thermal stratification to provide refuge for two fish species in the San Francisco Estuary (SFE): Chinook Salmon (Oncorhynchus tshawytscha) and Delta Smelt (Hypomesus transpacificus). We compiled water temperature data from multiple monitoring programs to evaluate spatial, daily, hourly, intra-annual, and inter-annual trends in stratification using generalized additive models. We used our data and models to predict the locations and periods of time that the bottom of the water column could function as thermal refuge for salmon and smelt. Periods in which the bottom was cooler than surface primarily occurred during the peak of summer and during the afternoons, with more prominent stratification during warmer years. Although the SFE is often exceedingly warm for fish species and well-mixed overall, we identified potential for thermal refugia in a long and deep terminal channel for Delta Smelt, and in the periods bordering summer for Chinook Salmon. Thermal stratification may increase as the climate warms, and pockets of cooler water at depth, though limited, may become more important for at-risk fishes in the future.

\section{Introduction}

Estuaries are highly dynamic and diverse systems valuable to human populations due to the wide array of ecosystem services they provide (Barbier et al., 2011). Estuaries are also some of the most degraded ecosystems on the planet: tributary rivers have been dammed and diverted, food webs have been altered by invasive species, and 
contaminants have been introduced into the waters (Lotze et al., 2006). Many of these anthropogenic impacts are exemplified in the San Francisco Estuary (SFE) of California, United States (Nichols et al., 1986; Brown \& Bauer, 2010). The SFE has lost a large portion of its historical tidal wetlands due to diking, freshwater flow is largely controlled by water control infrastructures, and multiple native fish species are in severe decline (Kimmerer, 2004). Some species, such as the estuary-endemic Delta Smelt (Hypomesus transpacificus) and the anadromous Chinook Salmon (Oncorhynchus tshawytscha) are of particular interest due to their listing under the federal and California Endangered Species Acts (Perry et al., 2016; Moyle et al., 2018).

Water temperature is a key variable controlling the physiology, behavior, and distribution of fishes. Temperature can influence the growth rate, metabolism, and swimming activity of individual fish (Jobling, 1997; Breau et al., 2011; Jeffries et al., 2016; Davis et al., 2019a). These effects can impact fish species at a population level through increased predation-associated mortality or reduced spawning success (Rose et al., 2013; Davis et al., 2019b; Michel et al., 2020). Shifts in water temperature can also alter the routing and timing of migration and, therefore, can change the distribution of fishes at large geographical scales (Munsch et al., 2019; Goertler et al., 2021). Fish can exploit the spatial and temporal temperature variation within a system to optimize their bioenergetics (Bevelhimer \& Adams, 1993; Neverman \& Wurtsbaugh, 1994; Armstrong \& Schindler, 2013; Armstrong et al., 2013). They can also seek refuge (whether cooler or warmer) in order to avoid thermal stress or potentially lethal conditions (Torgersen et al., 1999).

Climate change is forecasted to increase water temperatures through atmospheric warming and in California, this will be exacerbated by declining snowpack in the wet season (i.e., winter) (Dettinger \& Cayan, 1995). In response to warming, marine fishes have been migrating towards higher latitudes while freshwater fishes have been migrating to higher elevations to seek better thermal conditions (Hickling et al., 2006; Comte \& Grenouillet, 2013). However, some species with limited opportunities for dispersal (e.g., spring and lake-dwelling fishes, estuary-specialist species with narrow abiotic tolerances) or anadromous species that rely on thermally suitable migration corridors may have few options for avoiding warming conditions (Ray, 2005). Evidence suggests that water temperatures are already reaching stressful levels for thermally-sensitive fishes in some areas of the upper SFE and that climate change will continue to increase water temperature over time (Brown et al., 2013, 2016; Bashevkin et al., 2021; Nobriga et al., 2021). Although modeling studies (Vroom et al., 2017) and observational studies (Brown et al., 2016) suggest that significant vertical differences in water temperature are likely uncommon in the upper SFE, the hypothesis that such thermal stratification can act as temporary refuge for aquatic species has not been well tested. Furthermore, assessment of thermal heterogeneity in the landscape can help better understand the ecology and evolution of the estuary's biota.

Here we seek to evaluate existing discrete (e.g., boat-based surveys) and continuous (e.g., sondes) records of water temperature in the SFE to determine the timing, frequency, duration, and magnitude of differences between near-surface and near-bottom water temperature. We compiled thousands of discrete temperature data points that have been collected since 2011 and data from four continuous monitoring stations that have been collected since 2012. These data were interpolated over space and time to identify patterns of thermal stratification. Our study questions are as follows: 1) Where on the landscape does thermal stratification occur?,2) When during the day and over the course of the year does thermal stratification occur?, and 3) Can thermal stratification provide refuge for fish species of concern? We specifically consider two species of management concern in the SFE: Delta Smelt and Chinook Salmon. Delta Smelt is an example of an estuarine resident species with limited capability to disperse to other estuaries (Sommer \& Mejia, 2013), while Chinook Salmon is an example of an anadromous species that relies on the SFE for only a part of its life cycle (Perry et al., 2016). Patterns of thermal stratification and its potential impacts to fish species described in this study can be instructive for other major estuaries around the world inhabited by thermally-sensitive and estuary-dependent fishes.

\section{Methods \\ Study system}

The SFE is the largest estuary on the Pacific Coast of the United States, stretching from the tidal saline San Francisco Bay to the tidal freshwater Sacramento-San Joaquin Delta (Delta) (Figure 1). This system has been highly altered by habitat modification, construction of water conveyance infrastructure, and species invasions (Nichols et 
al., 1986). Once composed of largely dendritic tidal wetlands and seasonal floodplains, the Delta of today is a network of diked channels bordered by levees built to protect agricultural tracts (Whipple et al., 2012). The Delta is managed to be mostly freshwater year-round, with some brackish water (1-2 parts per thousand salinity) intruding in the western Delta during the summer and fall of dry years. Salinity is managed through upstream reservoir releases, as well as adjustments to water exports at the pumping facilities in the southwestern Delta near Old and Middle Rivers. The SFE downstream of the Delta is dynamic in salinity and the low salinity zone between 1 and 6 ppt is of particular interest to managers due to the association of the endangered Delta Smelt with this habitat (Sommer \& Mejia, 2013). The SFE has a Mediterranean climate with warm and dry conditions in the summer and fall (JuneOctober) and cold and wet conditions in winter and spring (November-May). The amount of precipitation and flow in the SFE varies considerably from year to year. This high interannual variability plays a significant societal and ecological role in California (Dettinger et al., 1998). Temperature in the SFE is typically highest in July and lowest in January.

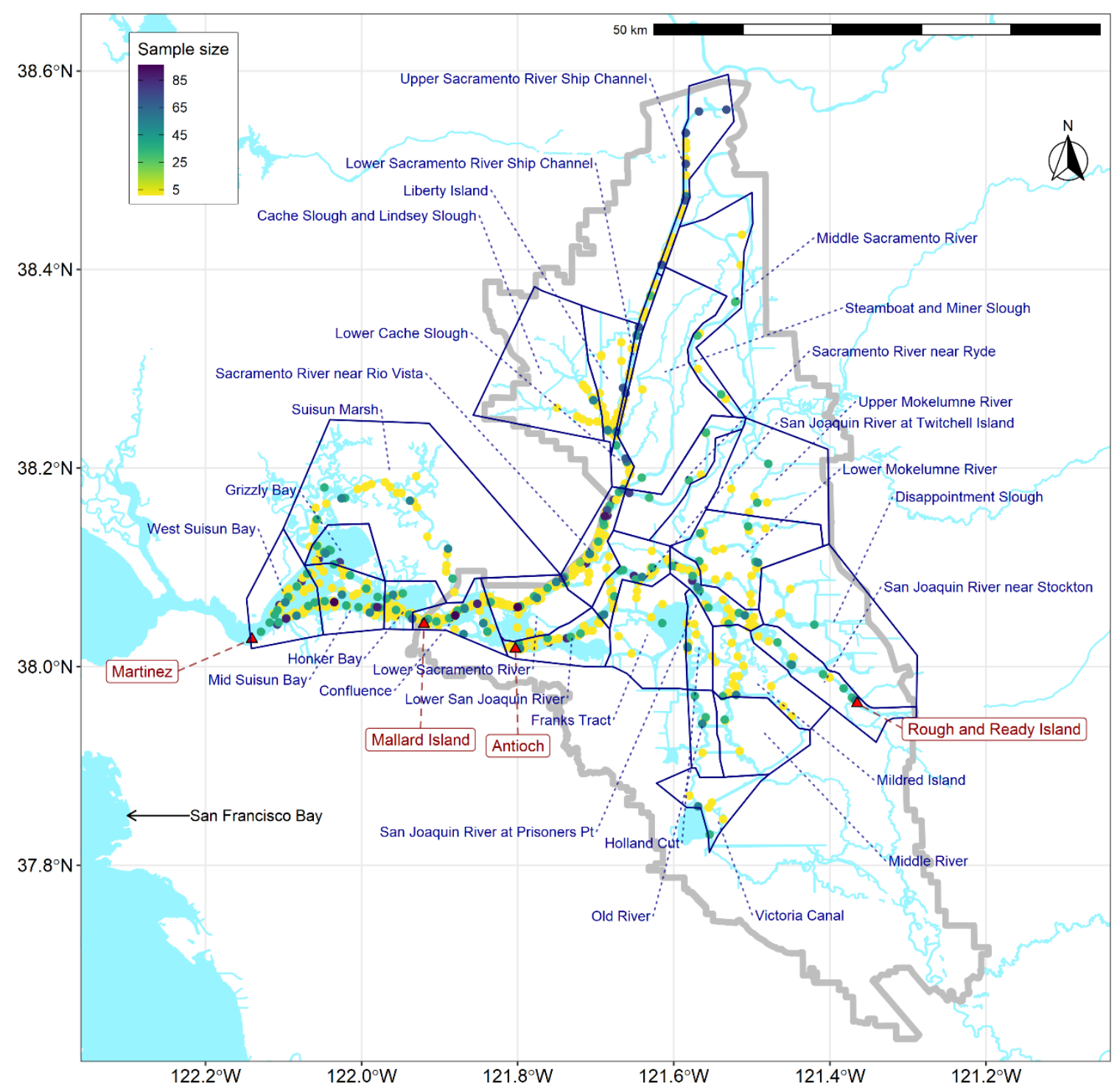

Figure 1. Map of the upper San Francisco Estuary, California, USA, along with sampling locations. Circles indicate locations where discrete water temperature measurements were taken and colored based on sample size. Red 
105

106

107

108

109

110

111

112

113

114

115

116

117

118

119

120

121

122

123

124

125

126

127

128

129

130

131

132

133

134

135

136

137

138

139

140

141

142

143

144

145

146

147

148

149

150

151

152

153 outline denotes the legal Delta boundary. Note that region cutoffs were used only for data processing and visualization purposes (not for analyses).

Data source

Discrete dataset

We integrated water temperature data collected at discrete time points in the SFE from various boat-based monitoring programs and studies (Bashevkin, 2021). Further details on the data integration process and access to the data can be found in Bashevkin (2021). For this study, we only retained data with temperature measurements at both the surface and near-bottom of the water column (typically $0.5 \mathrm{~m}$ below the surface and $0.5 \mathrm{~m}$ above the bottom). Data containing both surface and bottom temperature information has limited spatial coverage prior to 2011. Therefore, we only used data from 2011 to 2019 . We removed a few data points which appear to have been entered incorrectly (i.e., more than $8{ }^{\circ} \mathrm{C}$ difference between the surface and the bottom or data with spatial coordinates that are outside of the SFE's water boundaries). We also excluded data from regions with limited sample size (i.e., regions with no station containing 25 or more sampling occasions; see Figure 1 for regional boundaries). To reduce spatiotemporal autocorrelation in the dataset, in cases where multiple samples were taken at a single location in a day, only a single sample was retained (the data point closest to 12 P.M. was chosen). The final discrete temperature dataset contained 9,463 data points from seven different SFE studies: the Fall Midwater Trawl survey (Stevens \& Miller, 1983), the San Francisco Bay study (Armor \& Herrgesell, 1985), the Summer Townet survey (Turner \& Chadwick, 1972), the Environmental Monitoring Program (IEP et al. 2021), the Enhanced Delta Smelt Monitoring survey (USFWS et al. 2020), the U.S. Bureau of Reclamation's Sacramento Deepwater Ship Channel survey (Bashevkin, 2021), and the U.S. Geological Survey’s San Francisco Bay survey (Schraga \& Cloern, 2017).

\section{Continuous dataset}

We integrated continuous surface and bottom water temperature data from four stations monitored by the California Department of Water Resources. Stations included: Antioch (ANH) in the San Joaquin River, Mallard Island (MAL) in the confluence area of the Sacramento and San Joaquin Rivers, Martinez (MRZ) at Carquinez Strait, and Rough and Ready Island (RRI) in the San Joaquin River at the Port of Stockton (Figure 1). All bottom sensors were approximately 1 meter from the bottom of the riverbed, and all surface sensors were near the surface of the water column at a depth of approximately 3-4 meters. Surface temperature data were filtered for relevant stations from IEP et al. (2020). Bottom temperature data were standardized and quality checked as described by IEP et al. (2020), including filtering the 15-minute event data to hourly, and applying range, missing values, repeating values, anomaly, spike, and rate of change filters. Lastly, we filtered the dataset to a time period for which all stations had existing and paired surface and bottom temperature data. The final dataset contained 252,711 datapoints from November 2012 to October 2019.

Data analysis

\section{Discrete dataset}

We used generalized additive models (GAM) to analyze general spatiotemporal patterns of temperature stratification in the discrete dataset. We calculated surface-bottom temperature difference (surface temperature minus bottom temperature) and used it as a response variable. As such, negative values correspond to cooler temperatures towards the bottom and positive values correspond to warmer temperatures towards the surface. Covariates used include geographical coordinates (x, y) and day of year (1 for January $1^{\text {st }}$ and 365 or 366 for December $31^{\text {st }}$ dependent on whether it is a leap year). Because temperature stratification can be affected by changes in air temperature at the daily or interannual scale, we also included a "temperature anomaly" covariate that represents the variability of surface temperature relative to the expected daily temperature based on day of year and location. To calculate the temperature anomaly value, we first constructed a GAM to predict surface temperature based on day of year and geographical coordinates at a coarse level:

$S \sim \operatorname{te}((x, y),($ day of year $))$

where $S$ is the surface temperature $\left({ }^{\circ} \mathrm{C}\right)$, te is tensor product smooth, $x$ and $y$ are the geographical coordinates.

Smooth terms were thin plate regression spline and cyclic cubic regression spline for spatial coordinates and day of year terms, respectively. The GAM parameter $k$, the basis dimension of each smoother, was set to 5 for day of year 
154

155

156

157

158

159

160

161

162

163

164

165

166

167

168

169

170

171

172

173

174

175

176

177

178

179

180

181

182

183

184

185

186

187

188

189 and 10 for the spatial coordinates. These basis dimensions were set fairly low for the model because it was used mainly to remove collinearity between temperature, space, and time. To calculate the temperature anomaly value, we subtracted the observed temperature in our dataset by the predicted temperature from the temperature anomaly model. As such, the final temperature anomaly value provides us with the deviation of the surface temperature measurements from the general expectation based on their location and season within the SFE.

We set up four candidate models with smoother terms based on hypotheses (see models 1-4 in Table 1). A conventional thin-plate regression spline GAM with geographical coordinates as predictors would extrapolate the model across space without regards to geographical boundaries (e.g. prediction of water temperature over land). To minimize potential bleedover of information between distinct water bodies that are within a short distance of each other (e.g., eastern end of Suisun Marsh and western end of Cache and Lindsey Sloughs) (Figure 1), we applied a fourth model with a soap-film smoother (Wood et al., 2008) using the same covariates as the best fitting model out of the original four (Table 1). Because of the number of islands and channels that exist in the upper SFE, and the inability of the soap-film smoother to handle exceedingly complex boundaries, we ran our soap-film smoother model with a simplified boundary that represents just the outline of our study area (i.e., without islands) (Supplementary Information Figure S3). Because water temperature in the upper SFE is primarily driven by air temperature (Wagner et al., 2011; Vroom et al., 2017), a relatively simple boundary should have provided accurate results.

Prior to model selection, we conducted a preliminary analysis to select the best basis dimensions $(k)$ for each covariate. We selected $k$ of 5 for the day of year term based on visual inspection of the temperature anomaly calculation model and the general seasonal pattern of the system. For the spatial coordinates term (x,y), we constructed GAMs with surface-bottom temperature difference as the response variable and the tensor product smooth of the spatial coordinates as predictors with varying $k$. We constructed models from $k=10$ to $k=50$ at increments of 5, resulting in a total of nine models. We evaluated changes in adjusted $\mathrm{R}^{2}$ and Akaike information criterion for limited sample size (AICc) across the different $\mathrm{k}$ values to select the best $\mathrm{k}$. We selected $k=20$ for the spatial coordinates term based on the incremental change with subsequent increase of $k$ (Supplementary Information Figure S1). We followed a similar procedure to select $k$ for the temperature anomaly term, but the GAMs for this were constructed with the tensor product smooth of both spatial coordinates and temperature anomaly. A total of eight models were constructed with varying $k$ for the temperature anomaly term from $k=3$ to $k=10$, with $k$ for the spatial coordinates term set at 20 . We selected a low $k$ at 3 for the temperature anomaly term based on visual inspection of changes in adjusted $\mathrm{R}^{2}$ and AICc, and to also ease the interpretation subsequent model output (Supplementary Information Figure S2).

Table 1. Description and justification of the four candidate GAMs used to evaluate patterns in thermal stratification using the discrete dataset. Models are ordered by increasing complexity. $T$ is the surface-bottom temperature difference, te is tensor product smooth, $x$ and $y$ are the spatial coordinates, day is day of year, and ta is temperature anomaly. For smooth terms, $t p$ is thin plate regression spline, $c c$ is cyclic cubic regression spline, and $s o$ is soap-film smooth.

\begin{tabular}{|l|l|l|l|}
\hline $\begin{array}{l}\text { Candidate } \\
\text { model } \\
\text { number }\end{array}$ & Model structure & Smooth terms & Interpretation and hypothesis \\
\hline 1 & $T \sim t e(x, y)$ & $\mathrm{x}, \mathrm{y}=\mathrm{tp}$ & $\begin{array}{l}\text { Thermal stratification varies across } \\
\text { space, but not by season }\end{array}$ \\
\hline 2 & $T \sim t e((x, y),(d a y))$ & $\mathrm{x}, \mathrm{y}=\mathrm{tp}$, day $=\mathrm{cc}$ & $\begin{array}{l}\text { Thermal stratification varies by space } \\
\text { and season }\end{array}$ \\
\hline 3 & $T \sim t e((x, y),(d a y),(t a))$ & $\mathrm{x}, \mathrm{y}=\mathrm{tp}$, day $=\mathrm{cc}, \mathrm{ta}=\mathrm{tp}$ & $\begin{array}{l}\text { Thermal stratification varies by space, } \\
\text { season, and surface temperature } \\
\text { anomaly }\end{array}$ \\
\hline 4 & $T \sim t e((x, y),(d a y),(t a))$ & $\mathrm{x}, \mathrm{y}=\mathrm{so}$, day $=\mathrm{cc}, \mathrm{ta}=\mathrm{tp}$ & $\begin{array}{l}\text { Thermal stratification varies by space, } \\
\text { season, and surface temperature } \\
\text { anomaly. Water boundaries are also }\end{array}$ \\
\hline
\end{tabular}




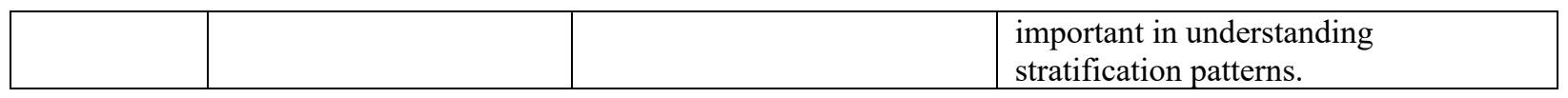

We assessed relative model fit of the four candidate models by using adjusted $\mathrm{R}^{2}$ and AICc (Table 1). To further evaluate the performance of the models, we conducted 10 -fold cross validations with randomly assigned folds to the dataset (but same across models). We assessed the results of this 10-fold cross validation process by calculating the root mean square error (RMSE) and Pearson's correlation coefficient $(r)$ between the out-of-sample predictions and observations. Global RMSE across folds was calculated by dividing the sum of squares of RMSE from the various folds by the number of folds (10), and then taking the square root of this value. We also calculated the proportion of predictions from the 10 -fold cross validation that had the same sign as the observed value (e.g., whether the model predicted a negative value when the observation has a negative value and vice versa). For this calculation, actual observations with identical bottom and surface temperatures (zero difference) were removed. To assess the degree of residual spatiotemporal autocorrelation, we calculated the spatiotemporal variogram on the best model's residuals (Pebesma, 2004).

To visualize our results, we first generated a $150 \times 150$ grid of cells over the spatial extent of our dataset. We then removed any points outside of the SFE water boundaries, and subsequently generated predictions from our best fitting model based on the specified covariate values. All analyses for the discrete dataset were conducted in R version 3.8.2 (R Core Team, 2021) using the "mgcv" package for GAM construction (Wood, 2011), "cvTools" for k-fold cross-validation process (Alfons, 2012), "gstat" for spatiotemporal variogram (Gräler et al., 2016), and "ggplot2", "ggpubr", and "sf" package for plotting and visualization (Wickham, 2016; Pebesma, 2018; Kassambara, 2020).

\section{Continuous dataset}

Our discrete dataset was collected only during daytime and each site was rarely sampled more than a few times in a given month. As such, we used the continuously collected data in our study to better understand the changes in temperature stratification throughout a diel cycle and across months. We calculated surface-bottom temperature difference in a similar manner as the discrete dataset (surface temperature minus bottom temperature for each time period). To evaluate how surface-bottom temperature differences varied across a diel cycle, we organized time of day into 3 categories based on hour (Pacific Standard Time): Early (00:00-07:59), Middle (08:0015:59), and Late (16:00-23:59). To assess changes across months we plotted surface-bottom temperature differences by day of the year with gam smooths constructed in ggplot in R with the formula:

$$
y \sim s(x, k=5, b s=\text { "cc") }
$$

where $y$ represents the surface-bottom temperature differences, $x$ represents the day of the year, $k$ represents the GAM basis dimension, and $b s=$ " $c c$ " defines a cyclical smooth type. We observed that substantial differences occurred only at two of our stations: RRI and MRZ (Figure 2). For this reason, we focused on RRI and MRZ stations for subsequent analysis. 


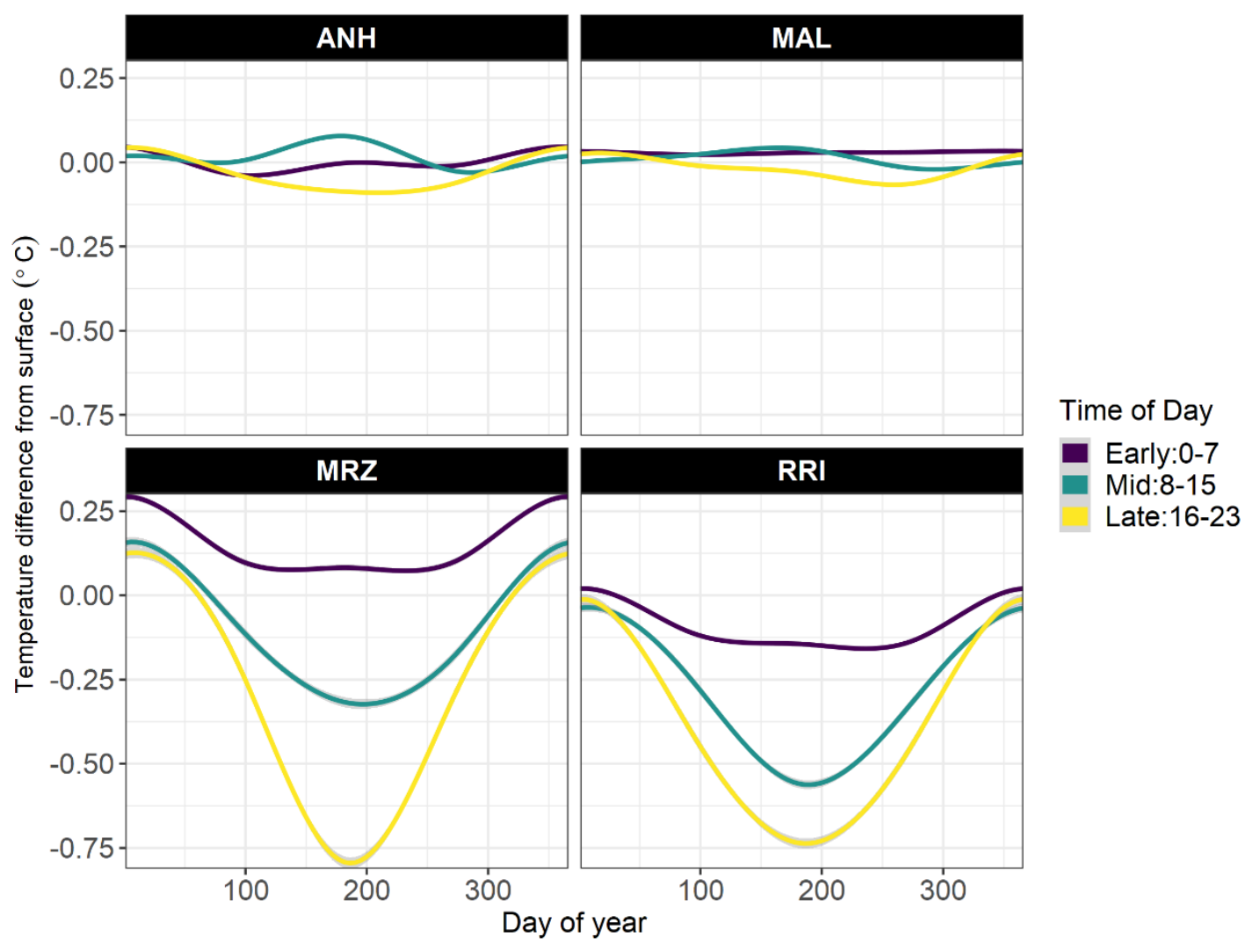

Figure 2. Results from preliminary analysis showing overall relative temperature difference between surface and bottom readings at four continuous water temperature stations: Antioch (ANH), Mallard Island (MAL), Martinez (MRZ), and Rough and Ready Island (RRI). Lines represent modeled temperature differences by day of year using GAM, and results are displayed for three time of day categories: Early (00:00 to 07:59), Mid (08:00-15:59), Late (16:00-23:59).

235

236

237

238

239

240

241

242

243

244

245

246

For models of RRI and MRZ, we first calculated surface temperature anomaly, similar to that described for the discrete dataset, to provide context about how relative temperature differences varied during cooler or warmer days. For each station, a GAM examining the interactive effect of day of year and hour on surface temperature was run. The basis dimension of each smoother, $k$, was set to a low k-value of 5 for both day of year and hour, and we used a cyclic cubic regression spline for both hour and day of year due to the cyclic nature of day of year and hour:

\section{$S \sim$ te(day of year, hour)}

The anomaly was then extracted from the response residuals of the model. Next, we ran separate models for RRI and MRZ examining the interactive effect of hour, day of year, and surface temperature anomaly on surface-bottom temperature difference $(T)$ using a tensor product smooth model. We recognized that there was temporal autocorrelation not accounted for in these models; however, we used the models primarily to visualize observed patterns. Basis dimension (k) values were selected based on our expectations and uses of this GAM model for visualization. We chose lower basis dimensions for hour and anomaly (7 and 6 respectively) because we expected simple curves and were only interested in the broader relationships. We chose a k-value of 14 for day-of-year to roughly reflect the monthly time-scale we were most interested in. We used a cyclic cubic regression spline for hour and day of year, and a thin plate regression spline for temperature anomaly $(\mathrm{ta})$ :

\section{$T \sim$ te(day of year, hour, ta)}

Model fit was assessed by visualizing residual patterns. We visualized model results by predicting model results for all combinations of hour (1-24), day of year (1-365 or 366), and surface temperature anomalies of $-1.5^{\circ} \mathrm{C}, 0{ }^{\circ} \mathrm{C}$, and 
$+1.5^{\circ} \mathrm{C}$, and plotting rasters of the results for each anomaly. Analysis for the continuous dataset was done in $\mathrm{R}$ version 4.0.1 (R Core Team, 2021). GAMs were run using the "bam" function in the "mgcv" package (Wood, 2011) and visualizations were displayed using the "ggplot2," "ggpubr", "grid" and "gridExtra" packages (Wickham, 2016; Auguie, 2017; Pebesma, 2018).

Species temperature metrics

To put our results in the context of species' habitat, we evaluated our data and model output using key temperature thresholds based on the existing literature for Delta Smelt and Chinook Salmon, two fish species of high conservation concern in the SFE. Delta Smelt is an endemic, annual forage fish species that spends the entirety of its life cycle in the upper SFE (i.e., estuary-dependent). High water temperatures in summertime can negatively impact Delta Smelt survival (Mac Nally et al., 2010; Polansky et al., 2020). Catch of Delta Smelt generally declines starting at $20^{\circ} \mathrm{C}$ and they are rarely seen when water temperature reaches $>25^{\circ} \mathrm{C}$ (Nobriga et al., 2008). Temperature of 25 ${ }^{\circ} \mathrm{C}$ and above is generally believed to cause high Delta Smelt mortality (Swanson et al., 2000; Brown et al., 2013, 2016), and therefore, we chose $25^{\circ} \mathrm{C}$ as our temperature cutoff for the species. Chinook Salmon is an anadromous fish species of high commercial and recreational interest that is native to the Pacific coast of North America. Adult Chinook Salmon spawn in rivers and juveniles mostly rear for a few months in streams and estuaries before making their way into the ocean. Juvenile Chinook Salmon face rising water temperature as they outmigrate, which results in increased predation risk. Mortality can be near $100 \%$ at or above $20^{\circ} \mathrm{C}$ due to predation (Nobriga et al., 2021) so we chose $20^{\circ} \mathrm{C}$ as our temperature metric for this species.

With the final models we constructed from our discrete dataset, we created surface and bottom temperature predictions that were converted to different suitability categories depending on the species (i.e., suitable temperatures at both surface and bottom, suitable only in the bottom of the water column, unsuitable overall). For Delta Smelt, we plotted temperatures during a typical condition (temperature anomaly $=0$ ) for July $15^{\text {th }}$, as this would generally be the hottest time of the year. For Chinook Salmon, we plotted temperatures during a typical condition (temperature anomaly $=0$ ) for June $15^{\text {th }}$ because this is the tail-end of the juvenile Chinook Salmon outmigration season and when they would experience the warmest conditions. We also constructed suitability plots with the continuous dataset for the two stations with substantial amount of stratification: MRZ and RRI. Continuous data allow us to better understand the true daily and seasonal pattern of temperature stratification that these at-risk fish species experience. We selected the year 2015 for the plots as this was the warmest average year in the dataset, representative of future conditions, with a relatively complete dataset for both MRZ and RRI stations. We calculated the proportion of each day that was below a threshold of $25^{\circ} \mathrm{C}$ for Delta Smelt and below $20^{\circ} \mathrm{C}$ for Chinook Salmon. We also subtracted the proportion of suitable hours at the surface by the proportion of suitable hours at the bottom to show when the bottom might provide refuge from the surface at each threshold temperature. While we acknowledge that these thresholds are somewhat arbitrary and that in truth a continuum of suitable temperatures exist for each species, a broad illustration of the thermal landscapes for each species during their warmest months can assist management agencies with identifying areas for potential recovery actions (e.g., supplementation, restoration, etc.).

Results

Discrete dataset

In the discrete temperature dataset, surface temperatures ranged from 5.6 to $29.6^{\circ} \mathrm{C}$ with a mean of $18.1^{\circ} \mathrm{C}$ and median of $19.2^{\circ} \mathrm{C}$, while bottom temperatures ranged from 5.6 to $29.9^{\circ} \mathrm{C}$ with a mean of $17.9^{\circ} \mathrm{C}$ and median of $19^{\circ} \mathrm{C}$. Temperature difference (surface temperature minus bottom temperature) in the discrete dataset ranged from 7.4 to $6.5{ }^{\circ} \mathrm{C}$ with a mean of $-0.2{ }^{\circ} \mathrm{C}$ (standard deviation of 0.6 ) and median of $-0.1{ }^{\circ} \mathrm{C}$. About $15 \%$ of the data had zero difference between surface and bottom temperatures. The surface temperature GAM constructed to calculate the temperature anomaly value followed our general expectations, with surface temperatures being highest in July and August and lowest in January (Supplementary Information Figs. S4-S6). Although there was some variability in the spatial pattern across seasons, surface temperatures were generally higher towards the Sacramento River Ship Channel to the north and the southern portion of the Delta (Figure 1, Figure 3). 

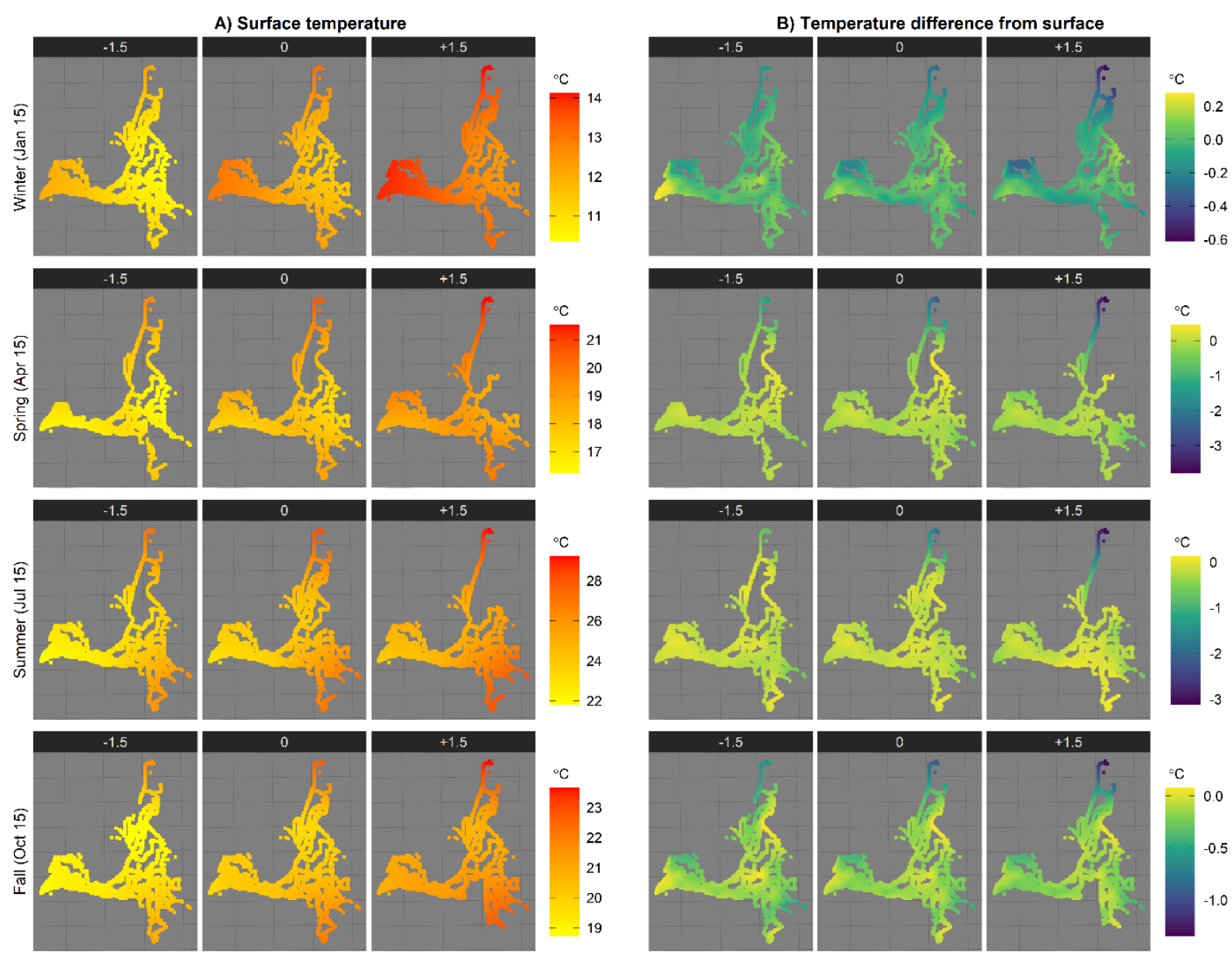

Figure 3. Model predictions of surface temperature and surface-bottom temperature differences over the waterways of the SFE with the discrete dataset. The surface temperature model outputs used to calculate the temperature anomaly are shown on the left panel, while the final soap-film smooth model results (model 4 in Table 1) are shown on the right panel. Rows are the dates that are used to represent the different seasons. Columns within each panel represent three different scenarios based on temperature anomaly values: cool conditions $\left(-1.5^{\circ} \mathrm{C}\right.$ from expected surface temperatures), average conditions ( 0 temperature anomaly, predicted surface temperatures), and warm conditions $\left(+1.5^{\circ} \mathrm{C}\right.$ from expected surface temperatures). To avoid extrapolation, only regions with data that match the categories (season and temperature anomaly group) are shown for each plot. Note that the color-temperature scale changes among seasons.

Of the four models we constructed with the discrete dataset (Table 1), model 4 with the soap-film smoother had the best fit overall with the best performance across all metrics except for percent of predictions with correct sign (Table 2). The temperature anomaly, which could be due to either diel or interannual changes in air temperature, appears to be an important variable for predicting surface-bottom temperature difference based on the substantial jump in $\mathrm{R}^{2}$, AICc, RMSE, and $r$ between model 2 and model 3. The addition of the soap-film smoother in model 4 provided only a modest improvement from model 3 based on the same metrics and negligible change in model accuracy based on $\%$ of correctly predicted directions of surface-bottom temperature difference ( + or -$)$. The spatiotemporal variogram of model 4 showed some autocorrelation for sites within $1 \mathrm{~km}$ of each other sampled on the same day, but no consistent patterns for other time frames or distance within a two-week span (Supplementation Information Fig S7). There was a slight increase in autocorrelation for data collected four weeks apart (Supplementation Information Fig S8), likely due to the nature of the long-term monitoring programs that produced the dataset where sampling occurs roughly once a month. 
316

317

318

319

320

321

322

323

324

325

326

327

328

329

330

331

332

333

334

335

Table 2. Summary of model fit metrics for the four candidate GAMs constructed with the discrete dataset as described in Table 1. Adjusted $\mathrm{R}^{2}$ and Akaike information criterion for limited sample size (AICc) were calculated from the full model. Root mean squared error (RMSE), Pearson's correlation coefficient ( $\mathrm{r}$ ) and \% of predictions with correct sign (+/-; observations of zero temperature difference removed) were calculated from the out-of-sample data through the 10 -fold cross-validation process.

\begin{tabular}{|c|c|c|c|c|c|}
\hline $\begin{array}{l}\text { Candidate } \\
\text { model } \\
\text { number }\end{array}$ & $\mathrm{R}^{2}$ & $\mathrm{AICc}$ & RMSE & $r$ & $\begin{array}{l}\% \text { of } \\
\text { predictions } \\
\text { with correct } \\
\text { sign }(+/-) \\
\end{array}$ \\
\hline 1 & 0.206 & 7856.6 & 0.510 & 0.511 & $74.7 \%$ \\
\hline 2 & 0.269 & 7013.9 & 0.487 & 0.569 & $76.1 \%$ \\
\hline 3 & 0.493 & 5602.5 & 0.402 & 0.708 & $77.3 \%$ \\
\hline 4 & 0.498 & 5571.9 & 0.388 & 0.731 & $77.3 \%$ \\
\hline
\end{tabular}

Both raw data and results from the soap-film model indicated that considerable differences $\left(>0.5^{\circ} \mathrm{C}\right)$ between surface and bottom temperatures are rare (Figure 4). Surface-bottom temperature difference tend to be negative (cooler in the bottom of the water column relative to surface), though conditions where bottom temperature is warmer than surface do occur in winter and spring. We observed the highest temperature differences between surface and bottom at the warmest conditions: during the peak of summer and as the temperature anomaly became more positive (Figure 3, Supplementary Information Figures S4-S6). Although the fall season saw lower magnitude temperature differences overall relative to summer, cooler temperatures in the bottom are more widespread than other seasons (Figure 4). Thermal stratification is the most prominent and consistent in the Sacramento River Ship Channel towards the northern end of the Delta, especially towards the northern tip of this dead-end channel. The Sacramento Ship Channel is where we observed the maximum temperature difference between surface and bottom in the discrete dataset at $-7.4^{\circ} \mathrm{C}$, and where the soap-film model predicted the highest difference overall with over 3 ${ }^{\circ} \mathrm{C}$ cooler temperatures in the bottom during the summer months. Although infrequent, the soap-film model indicates that warmer bottom temperatures can be observed relatively often at the western end of Suisun Bay during the coldest months and during more negative temperature anomaly conditions. 
Temperature difference from surface at $p<0.01$

Blue:Cooler than surface

Red:Warmer than surface
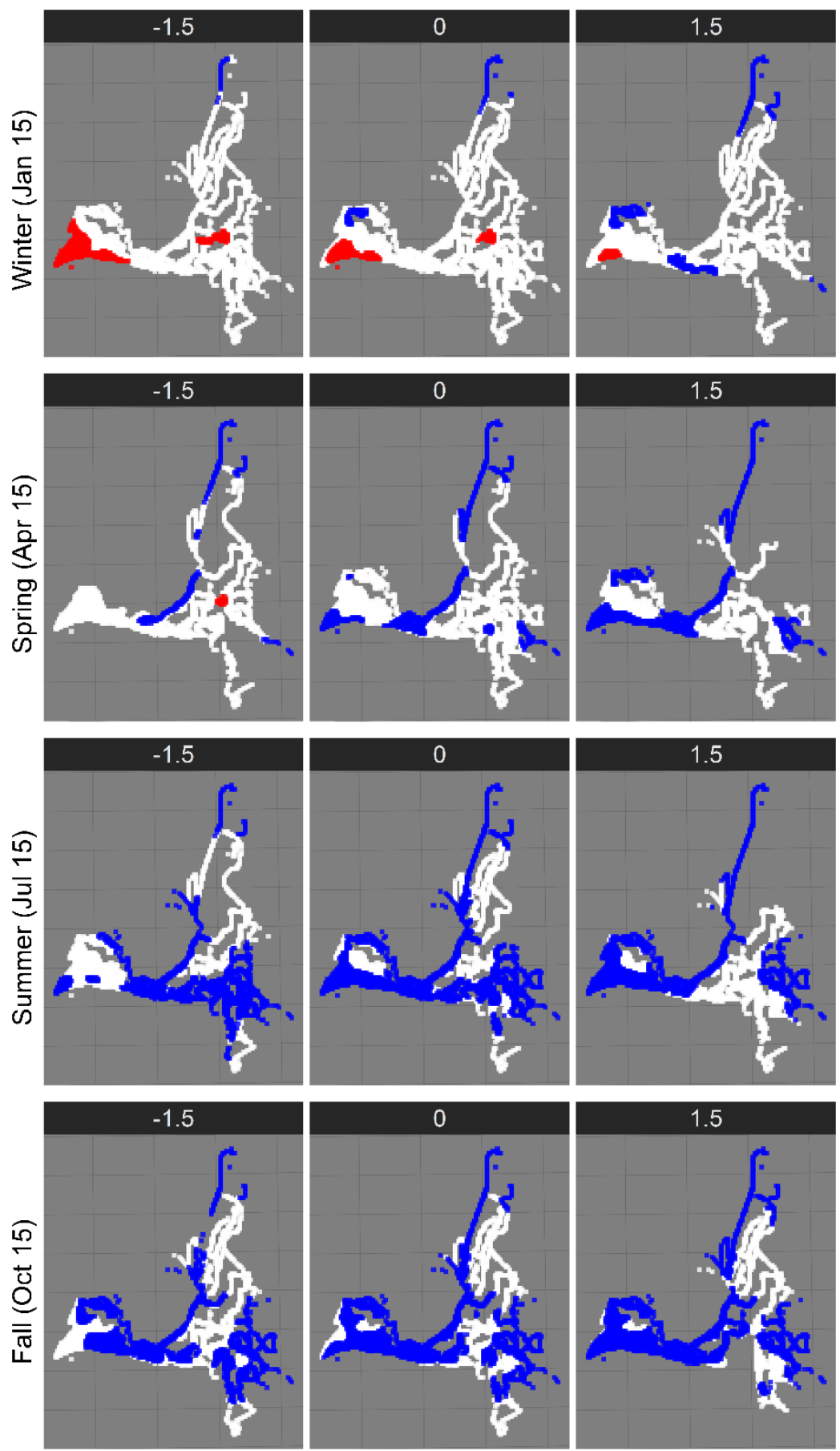

Figure 4. Model results for the discrete dataset showing areas with significant difference in temperature between surface and bottom $(\mathrm{p}<0.01)$ to aid interpretation of results. Red areas indicate warmer temperature in the bottom relative to surface, while blue areas indicate cooler temperature in the bottom relative to surface. Rows are the dates that are used to represent the different seasons. Columns within each panel represent three different scenarios: cool conditions $\left(-1.5^{\circ} \mathrm{C}\right.$ from expected surface temperatures), average conditions ( 0 temperature anomaly, predicted surface temperatures), and warm conditions $\left(+1.5^{\circ} \mathrm{C}\right.$ from expected surface temperatures). Only regions with data 
343

344

345

346

347

348

349

350

351

352

353

354

that match the categories (season and temperature anomaly group) are shown for each plot. The predicted mean magnitude of difference can be found in Figure 2.

\section{Continuous dataset}

For the entire continuous dataset, surface temperatures ranged from 6.6 to $28.8^{\circ} \mathrm{C}$ with a mean of $17.1^{\circ} \mathrm{C}$ and median of $17.6{ }^{\circ} \mathrm{C}$, while bottom temperatures ranged from 6.8 to $27.3{ }^{\circ} \mathrm{C}$ with a mean of $17.0^{\circ} \mathrm{C}$ and a median of $17.5^{\circ} \mathrm{C}$. ANH, MAL and MRZ had similar surface temperature ranges, while RRI had the greatest range and reached the highest temperatures of any station by several degrees (Table 3). ANH and MAL had more moderate surface-bottom differences, while MRZ and RRI exhibited greater negative values and variability in their surfacebottom differences (Figure 2; Table 3). For all stations, the highest temperature differences between surface and bottom usually occurred in the summer (June, July, August). Furthermore, median maximum temperatures occurred either during the $15^{\text {th }}$ or $16^{\text {th }}$ hour (3:00 or 4:00 PM in the afternoon).

Table 3. Temperature ranges for continuous stations.

\begin{tabular}{|l|l|l|l|l|}
\hline Station & $\begin{array}{l}\text { Surface Range } \\
\left({ }^{\circ} \mathrm{C}\right)\end{array}$ & $\begin{array}{l}\text { Bottom Range } \\
\left({ }^{\circ} \mathrm{C}\right)\end{array}$ & $\begin{array}{l}\text { Surface-Bottom } \\
\text { Difference Range } \\
\left({ }^{\circ} \mathrm{C}\right)\end{array}$ & $\begin{array}{l}\text { Surface-Bottom Difference Mean } \\
\pm \mathrm{SD}\end{array}$ \\
\hline Antioch (ANH) & $6.7-25.2$ & $6.8-25.1$ & $-1.9-2.4$ & $-0.01 \pm 0.14$ \\
\hline $\begin{array}{l}\text { Mallard Island } \\
\text { (MAL) }\end{array}$ & $7.1-24.2$ & $7.1-24.2$ & $-2.2-3.3$ & $0.01 \pm 0.14$ \\
\hline Martinez (MRZ) & $6.9-25.2$ & $7.7-23.7$ & $-5-4.4$ & $-0.08 \pm 0.53$ \\
\hline $\begin{array}{l}\text { Rough and } \\
\text { Ready Island } \\
\text { (RRI) }\end{array}$ & $7.2-28.8$ & $7.3-27.3$ & $-4-0.6$ & $-0.27 \pm 0.45$ \\
\hline
\end{tabular}

Results from the GAMs further indicate that for RRI and MRZ, bottom temperatures can be several degrees cooler than surface temperatures, especially during the summer (July - early September), and in the afternoon, (14:00 -19:00) (Figure 4, Figure 5). These differences, where bottom is cooler than surface, occur for $35 \%$ and $23 \%$ of predicted values in RRI and MRZ, respectively, but differences more negative than $-1{ }^{\circ} \mathrm{C}$ occur in only $3.4 \%$ and $4.7 \%$ of predicted values in RRI and MRZ, respectively. During cooler times of year, and the early and late hours of the day, we often observe no surface-bottom temperature difference, or the surface being slightly warmer than the bottom (up to $0.3{ }^{\circ} \mathrm{C}$ at RRI and $0.7^{\circ} \mathrm{C}$ at MRZ).

While RRI and MRZ exhibit similar patterns by day of year and hour, we observed differences in patterns in relation to surface temperature anomaly. MRZ exhibits similar trends as those observed in the discrete dataset: surface-bottom temperature differences are greater during warmer than expected surface temperatures (greater anomaly), reaching differences of $-2.3^{\circ} \mathrm{C}$ in the summer at a positive anomaly of $+1.5^{\circ} \mathrm{C}$ (Figure 5). For RRI, we observe the greatest surface-bottom temperature difference $\left(-2.5^{\circ} \mathrm{C}\right)$ during cooler than expected surface temperatures (anomaly of $-1.5^{\circ} \mathrm{C}$ ), followed by warmer than expected surface temperatures $\left(-1.4{ }^{\circ} \mathrm{C}\right.$ difference at an anomaly of $+1.5^{\circ} \mathrm{C}$ ) (Figure 5). 

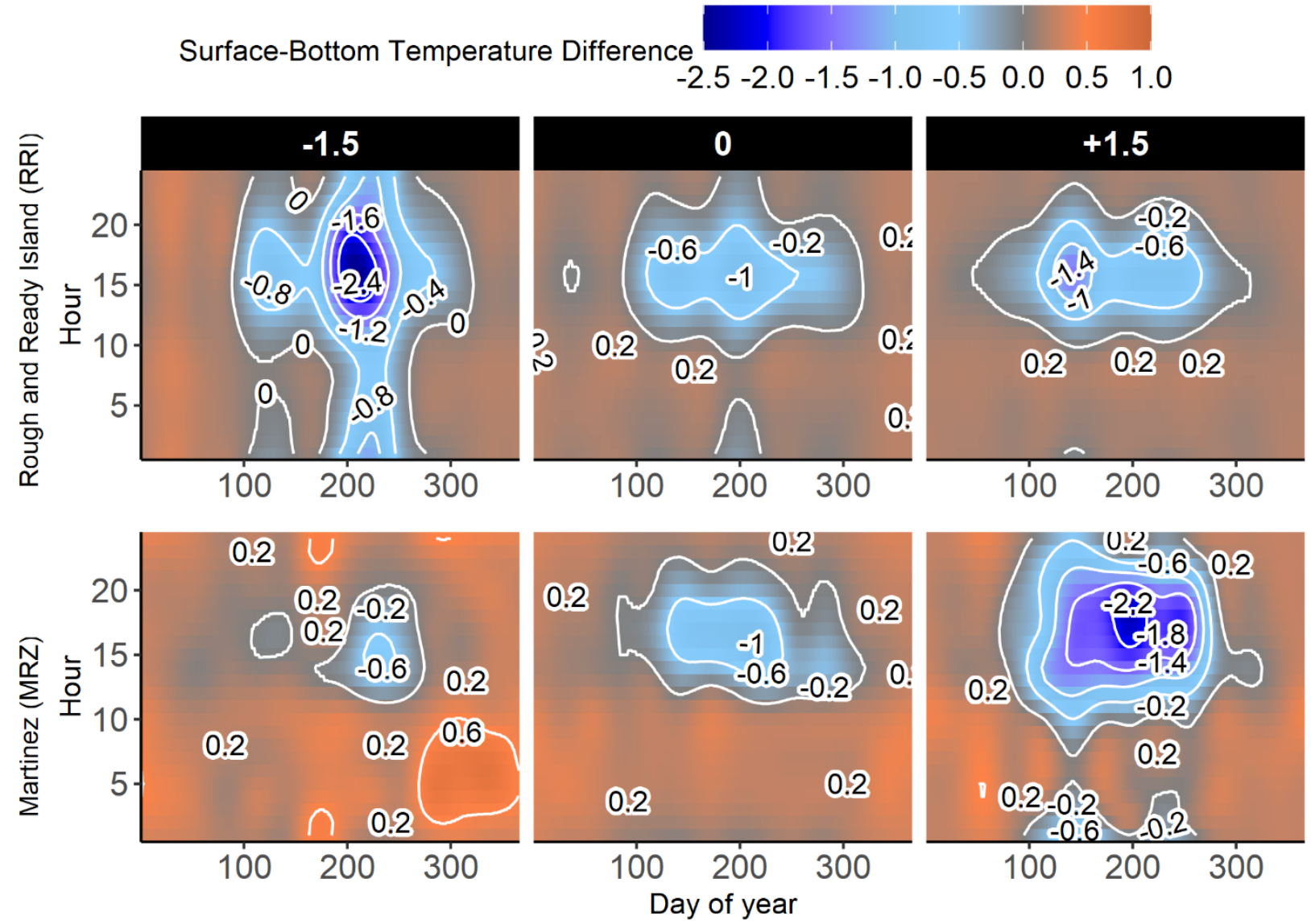

372

373

374

375

376

377

378

379

380

381

382

383

384

385

386

387

388

Figure 5. Model results for the continuous dataset showing trends in surface-bottom temperature difference by time of day (hour) and time of year (day of year) at RRI (top row) and MRZ (bottom row). Red areas indicate surface is cooler than bottom, and blue areas indicate bottom is cooler than surface. Columns within each panel represent three different scenarios based on temperature anomaly values: cool conditions $\left(-1.5^{\circ} \mathrm{C}\right.$ from expected surface temperatures), average conditions ( 0 temperature anomaly, predicted surface temperatures), and warm conditions $\left(+1.5^{\circ} \mathrm{C}\right.$ from expected surface temperatures $)$.

\section{Species temperature metrics}

Based on our surface temperature model and soap-film model results from the discrete dataset, the Sacramento River Ship Channel and the southern portion of the Delta are two regions that can pose thermal risk to both juvenile Chinook Salmon and Delta Smelt for the average June and July conditions (Figure 6). Parts of the Sacramento River (Middle Sacramento River region) towards the northeastern portion of our study region also seem to be relatively warm; however, we have low sample sizes for June and July for this area $(\mathrm{N}=9)$. Water temperatures were generally cooler at the bottom and may provide refuge in portions of the Sacramento Deepwater Ship Channel and the upper Sacramento River, representing habitat for Delta Smelt and key migration corridor for Chinook Salmon, respectively. Meanwhile, the southern edge of the Delta seems to offer little reprieve for both species with high temperatures above our thresholds for both surface and bottom of the water column during June and July of the average year.

The continuous dataset provided a similar picture, where the bottom of the water column can be cooler and more suitable for both at-risk species at different times of year (Figure 7). While both the surface and bottom are at temperatures likely unsuitable for both species throughout July-September for MRZ, and May-October for RRI, the bottom may provide periods of refuge during the months bordering these hottest months, such as in June and October for MRZ, and May and November for RRI (Figure 7). Juvenile Chinook Salmon will likely be downstream 
of Suisun Bay by July (MRZ), so the species would not be too affected by the warm temperatures in JulySeptember. However, Chinook Salmon may be affected by warmer temperatures in April in RRI, as this overlaps with their outmigration period from the San Joaquin River. As such, Chinook Salmon could take advantage of available bottom refuge during this period. Delta Smelt are unlikely to stay in MRZ all year due to the typical increases in salinity during the drier months, but they could be present during earlier parts of the summer and take advantage of available bottom refuge at this time. While both MRZ and RRI stations remained below $25^{\circ} \mathrm{C}$ throughout the summer of 2015, Delta Smelt can experience stress at temperatures lower than $25^{\circ} \mathrm{C}$ and may take advantage of cooler bottom temperatures when available.

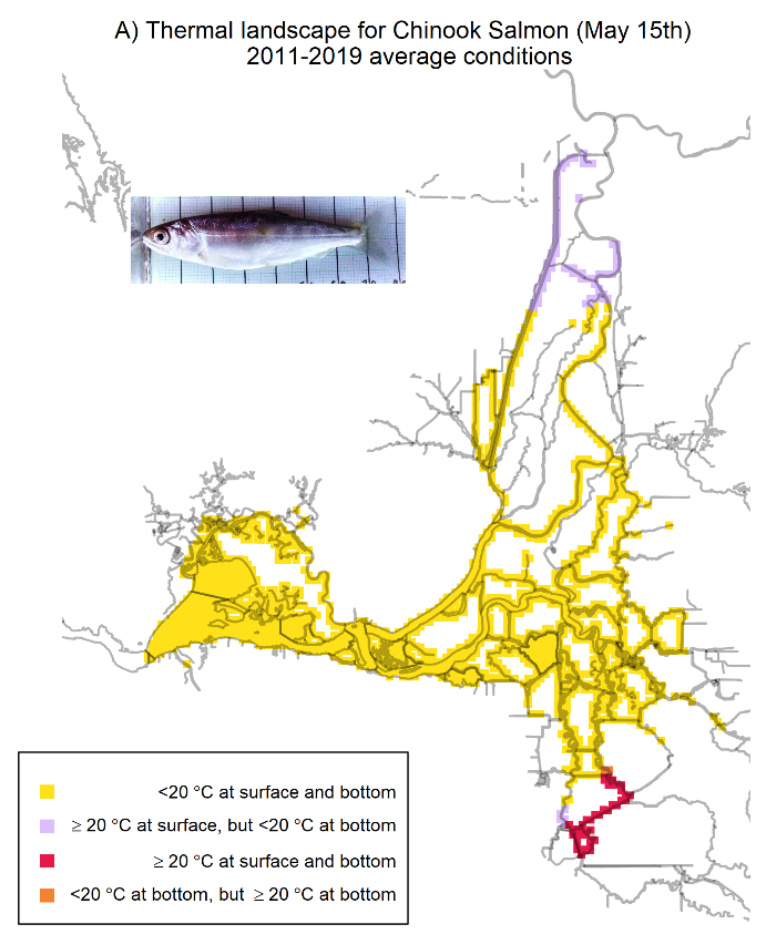

C) Thermal landscape for Chinook Salmon (May 15th)
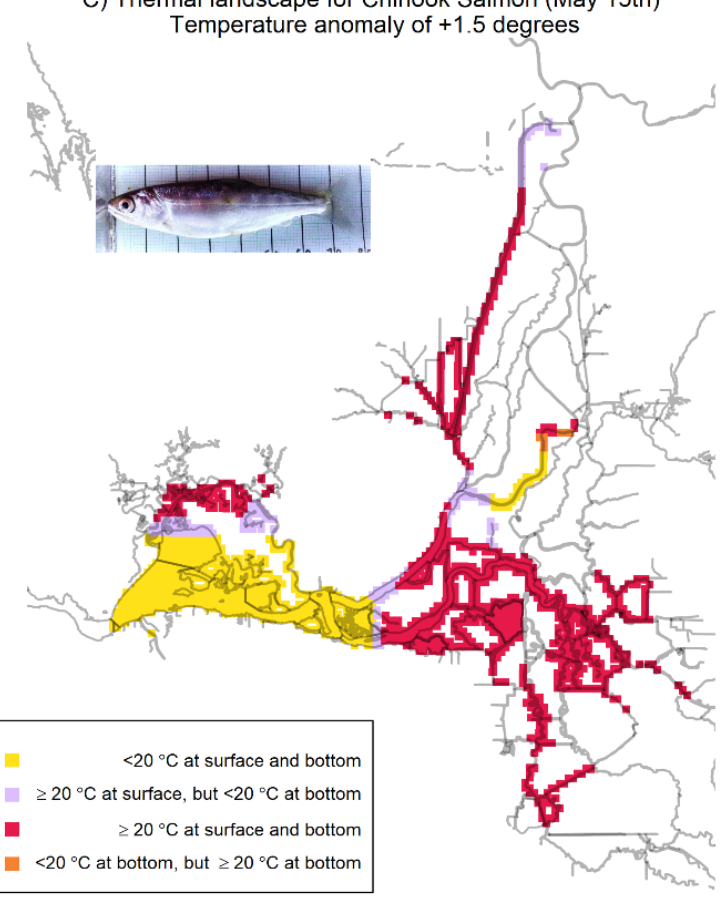
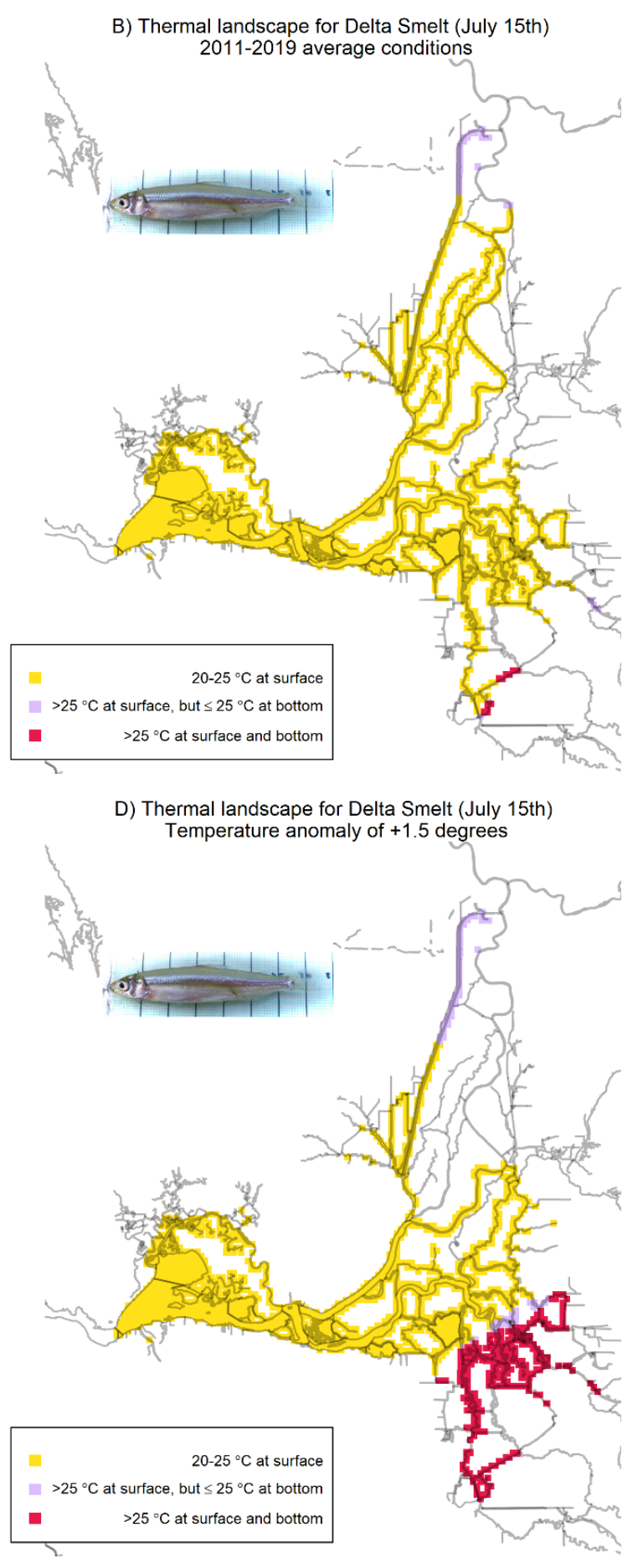
Figure 6. Temperature suitability maps for juvenile Chinook Salmon (A, C) and Delta Smelt (B, D) based on the warmest month that each species generally encounters in the upper SFE. For each species, the thermal landscape is plotted for average temperature conditions (plots A and B) and for warmer than average conditions (plots C and D). Plots were created with model predictions from the soap film model fit to the discrete dataset. Photo credit: Naoaki Ikemiyagi.
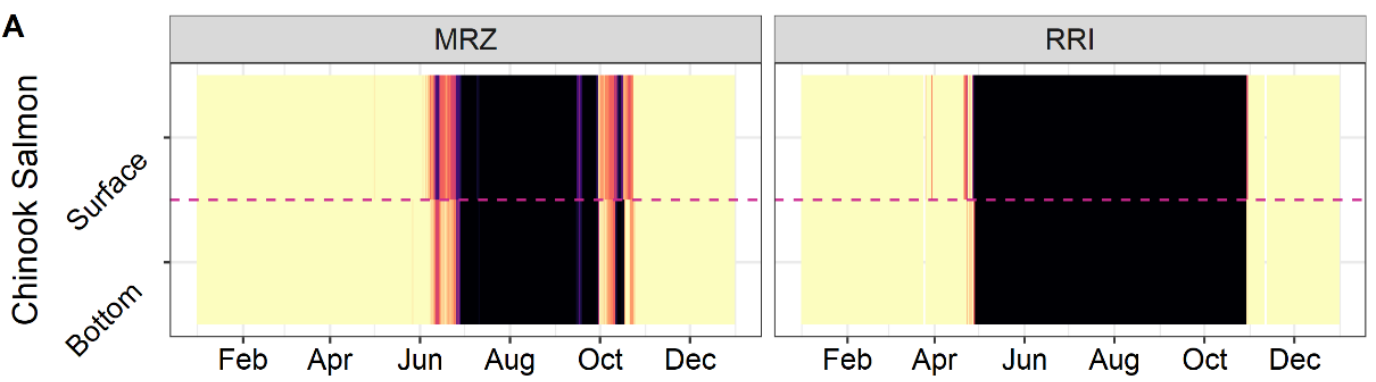

Proportion of time temperature was $<20^{\circ} \mathrm{C}$
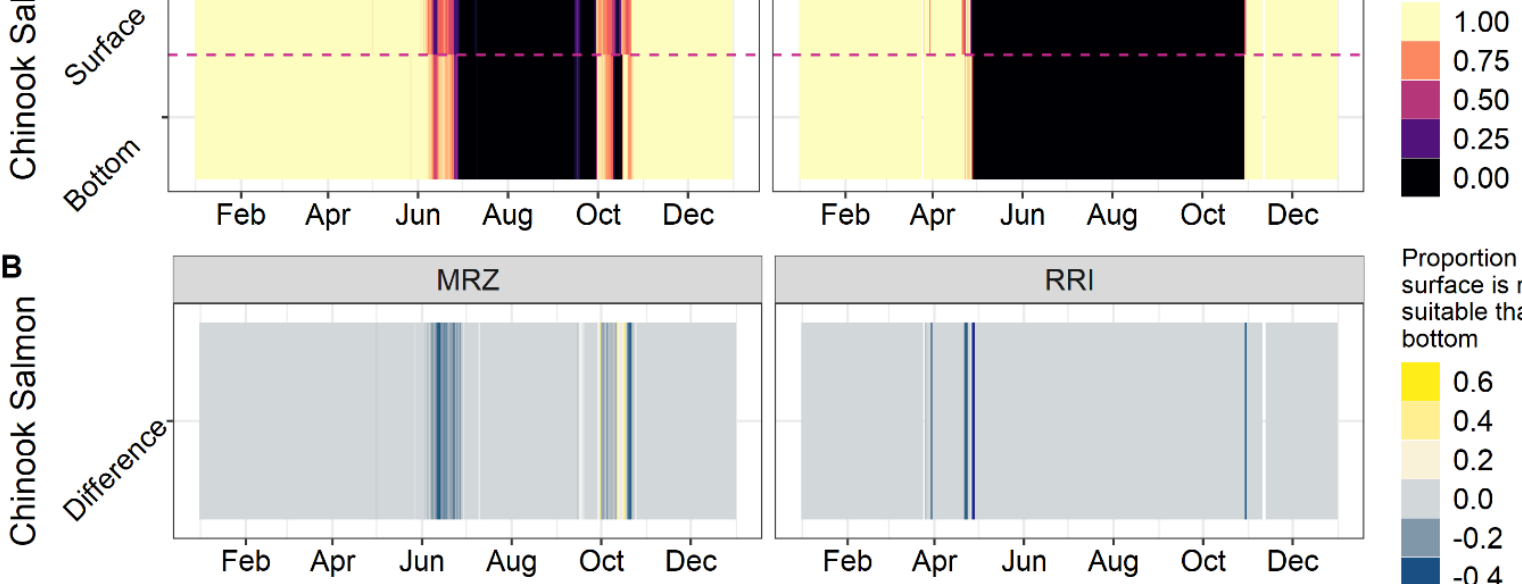

Proportion of time surface is more suitable than bottom
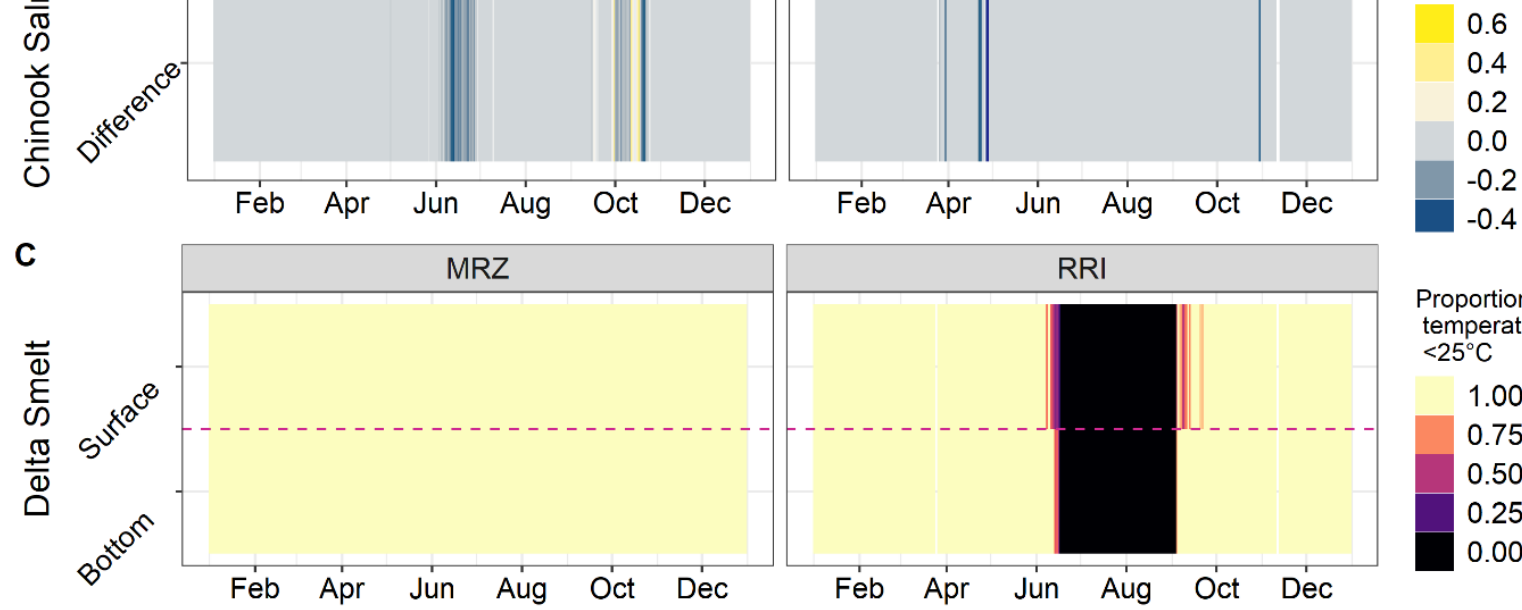

Proportion of time temperature was $<25^{\circ} \mathrm{C}$
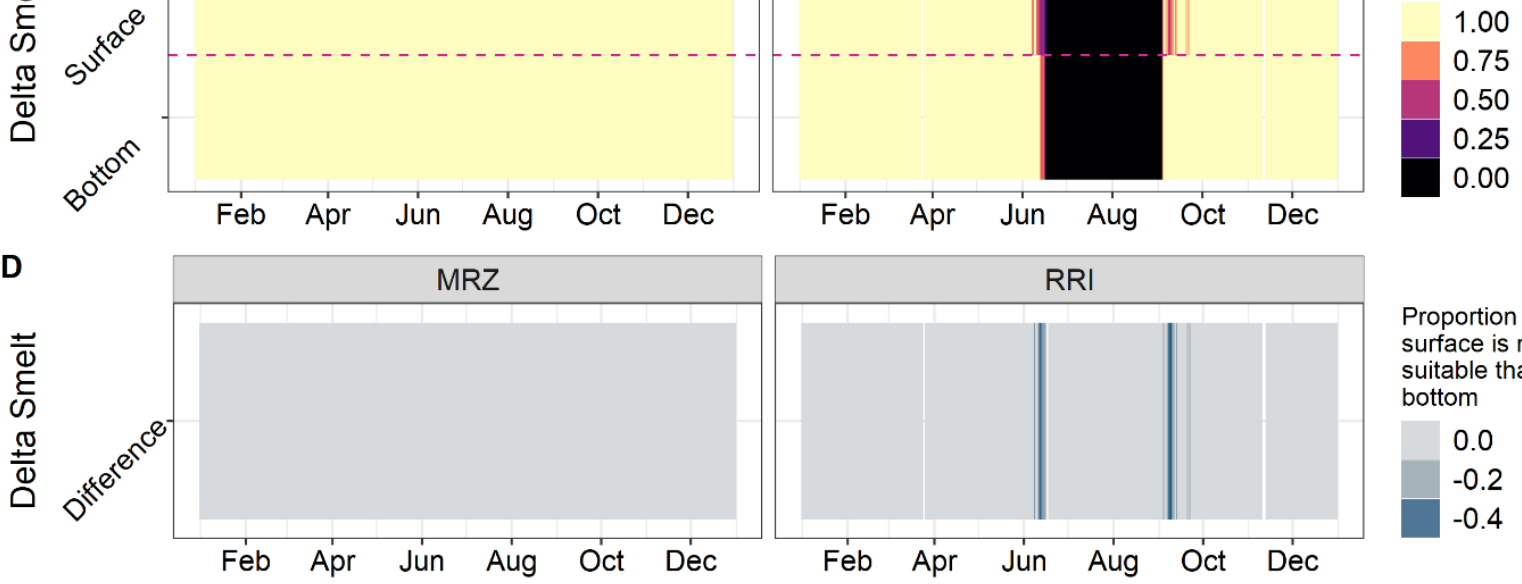

Proportion of time surface is more suitable than bottom

0.0

$-0.2$ $-0.4$

Figure 7. Temperature suitability heat map plots for Delta Smelt and juvenile Chinook Salmon in 2015. Data are from two continuous monitoring stations (MRZ and RRI) that demonstrated considerable thermal stratification. Plots display proportion of each day that is suitable based on thresholds of $20{ }^{\circ} \mathrm{C}$ for Chinook Salmon and $25{ }^{\circ} \mathrm{C}$ for Delta Smelt. For each species, surface and bottom suitability are plotted (A for Chinook Salmon, C for Delta Smelt). Surface-bottom suitability difference (B for Chinook Salmon, D for Delta Smelt) shows the difference between surface suitability and bottom suitability. Negative values (darker blues) indicate more hours of suitable bottom temperatures compared to the surface.

Evidence of climate change and its impacts on biodiversity continues to accumulate. However, these impacts will not be uniform across space and time, and the spatial and temporal variability in temperature stratification within estuaries may provide an important thermal refuge to key fish species. Our study shows that the 
420

421

422

423

424

425

426

427

428

429

430

431

432

433

434

435

436

437

438

439

440

441

442

443

444

445

446

447

448

449

450

451

452

453

454

455

456

457

458

459

460

461

462

463

464

465

466

467

468

upper SFE, while mostly well-mixed, shows episodic thermal stratification at certain locations, seasons, and times of day that may provide thermal refugia for at-risk species. Cooler water towards the bottom can be observed more often when overall temperatures are the highest: summer and fall months, warmer than average years, and the warmest time of the day. Our study also provides some insights into thermal stratification patterns that could be occurring in other estuarine systems with similar climate and geomorphology: during winter when freshwater outflow is high, warmer waters towards the bottom could occur (possibly related to salinity stratification), while deep terminal channels may result in a fairly consistent thermally-stratified water body throughout the year. Moreover, we took a statistical and empirical approach in this study that not only allows for a better understanding of the variability of thermal stratification, but also provides support and validation for mechanistic physical models.

Water temperature dynamics

Although it is generally well-understood that overall water temperatures are rising due to climate change, the thermal landscape may be complex. Results from our spatially-intensive discrete dataset indicate that thermal stratification varies considerably across space and time. When thermal stratification occurs, it often results in cooler temperatures in the bottom layer of the water column relative to the surface (Figure 4, Figure 5), as would be predicted from studies of other estuaries (Strange, 2013; Weinke \& Biddanda, 2019). Warmer water is less dense, so it rises in the water column. In addition, surface water is exposed to more sunlight and warm air temperatures compared to deeper water (Simpson et al., 1990).

The cooler bottom layer of water is the most consistent and widespread in the warm summer-fall months when freshwater input to the system is typically at its lowest. In highly stratified estuaries with a salt wedge, freshwater flow can intensify stratification by forming a buoyant layer on top of higher-density and colder salt water (Simpson et al., 1990). However, in shallower, fresher estuaries such as the Delta, freshwater flow may increase mixing. This pattern has also been seen in the Chesapeake Bay, where high freshwater flows can cause mixing and breakdown of stratification (Xu et al., 2012).

The bottom layer of the water column also becomes cooler relative to the surface as overall surface conditions become warmer (as proxied by the positive temperature anomaly value), possibly because thermoclines tend to form more frequently during periods of low wind, which often coincide with warmer air temperature. Surface water temperatures are also generally warmer in spring and summer during droughts, which can potentially increase thermal stratification (Bashevkin \& Mahardja, 2021). Conversely, warmer conditions towards the bottom of the water column can occur during cool conditions. The SFE typically experiences higher freshwater outflow in winter-spring relative to summer-fall, and longer exposure of the freshwater surface layer to cold air during wintertime may explain this phenomenon. Observations of warmer water in the bottom relative to surface are most common at the most downstream location of our study area during wintertime of colder years (Figure 4), likely a byproduct of salinity stratification that can take place in this more marine-influenced region (Vroom et al., 2017).

In concordance with previous studies (Kimmerer, 2004; Vroom et al., 2017), the magnitude of temperature difference from thermal stratification in the SFE is low in general (within $0.5^{\circ} \mathrm{C}$ ). The sole exception to this is the Sacramento River Ship Channel, a man-made channel built in 1963 to allow large vessel access to the port of West Sacramento, located towards the northern end of the Delta. The Sacramento River Ship Channel is a deep ( 11 meters) and long ( $\sim 40$ kilometers) dead-end slough with high residence time and low water exchange with the rest of the system (Gross et al., 2019). However, the Sacramento River Ship Channel is also tidally influenced towards its downstream portion, resulting in unique hydrodynamics relative to the rest of the Delta and a strong thermocline throughout most of the year (roughly between 0.6 to $3.5^{\circ} \mathrm{C}$ cooler towards the bottom, with a maximum of $7.4{ }^{\circ} \mathrm{C}$ based on our dataset). It is important to note that our discrete dataset can only demonstrate the broad spatiotemporal patterns and cannot capture the short-term variability in thermal stratification due to tides and winds. Thermal stratification in the Sacramento River Ship Channel is more prevalent during ebb tides when warm water from the northern end moves south at the surface layer level (RMA, 2021). Meanwhile wind can break down thermal stratification due to vertical mixing at the Sacramento River Ship Channel (Lenoch et al., 2021). Changes to wind patterns due to climate change could impact where and when we see thermal stratification in the future. It is possible that the declining wind speed observed in the estuary (Bever et al., 2018) may have further amplified the thermocline seen at the Sacramento River Ship Channel. Wind has been well-documented in breaking down 
stratification in other estuaries, including the Chesapeake Bay (Xu et al., 2012), Great Lakes (Weinke \& Biddanda, 2019), and the York estuary (Scully et al., 2005).

The temporally-intensive, but spatially limited continuous water temperature data provides an important counterpoint to our spatially-intensive discrete data set. We found the potential for greater average temperature differences at two of the continuous site sites than the discrete data would suggest, possibly because it captures more data from the warmest part of the day ( 14:00-16:00). These stations also gave us a window into nighttime temperature patterns, which are not captured during discrete water quality sampling runs. Higher stratification during warmer times of day is not surprising, but the difference between the four continuous stations was unexpected, and provides insight into the range of potential thermal landscapes. Station MRZ was furthest to the west, more subject to ocean influence, and had the highest range of difference between surface and bottom temperatures. There were even periods of early mornings during the winter when bottom temperatures were warmer than surface temperatures, potentially due to an interaction between thermal stratification and salinity stratification (Cloern et al., 2017). RRI was furthest to the east, but in a much smaller channel. High stratification was observed at this site as well, particularly in the summer in the afternoon. The moderate amount of thermal stratification observed at RRI may due it being a deep channel with low water velocity for large parts of the year (Vroom et al., 2017). ANH and MAL were midway between these two end points, and these two stations had very little thermal stratification. We do not have sufficient sample size to speculate on which conditions are controlling these patterns, but the contrast between these four stations indicates more paired surface/bottom continuous temperature sensors can help better understand the thermal landscape of the estuary.

Another interesting observation from the continuous temperature sensors was that while surface-bottom temperature difference increased with temperature anomaly at MRZ, as expected from surface warming, we did not observe this pattern at RRI. The increased stratification during cooler years may be related to inflow and water year type, as the coolest years observed at this station also happen to be the wettest years $(2017,2019)$, and similarly, the warmest years also happen to be some of the driest years in our study period (2014-2016) (Supplementary Information Figures S12, S13). Meanwhile, the decreased stratification during warmer periods may be due the interaction between inflow and the exceptional longitudinal dispersion observed in the San Joaquin River where RRI station is located (Monismith et al., 2009). This phenomenon may also be related to the Stockton Deep Water Ship Demonstration Dissolved Oxygen Aeration Facility (Aeration Facility) pumping that occurs at RRI during warmer years and during times of lower levels of dissolved oxygen, which may increase vertical mixing. The intake for the Aeration Facility is at the same location as the RRI water quality station and the diffuser location is approximately 0.2 miles downstream of RRI (ICF International, 2010). Pumps or "bubblers" are commonly used to mitigate local occurrences of low dissolved oxygen levels and have been found to disrupt stratification of temperature and salinity in other systems (e.g., Hamilton et al., 2001).

Implications for species of concern

Identifying thermal refugia for key species under a warming climate is a critical issue for conservation biology (Keppel et al., 2012). In the SFE, two declining fish species play a substantial role in water management and are of high interest: Chinook Salmon and Delta Smelt. Chinook Salmon is an ecologically and economically important species throughout the Pacific coast of North America, with two federally-listed runs under the Endangered Species Act within the SFE (NMFS, 2019). Meanwhile, the Delta Smelt is an annual, forage pelagic fish endemic to the SFE that is also federally listed and may be nearly extinct in the wild (Hobbs et al., 2017). Both fish species are considered sensitive to warm water temperatures $\left(>20^{\circ} \mathrm{C}\right)$ often seen in the SFE (Myrick \& Cech, 2004; Moyle et al., 2016). Based on our results, the northern and southern edges of the Delta already pose thermal risk in late-spring and summer for both Chinook Salmon and Delta Smelt based on the average conditions from the past decade (Figure 6). However, the impacts of these high temperature conditions and stratification differ considerably between the two species given their distinct life histories.

Chinook Salmon are most sensitive to temperature stress at their juvenile life stage, as they migrate from their spawning grounds in the upper watershed through the Delta on their way to the ocean. This stage in their migration is generally characterized by high mortality, even during good conditions (Buchanan et al., 2018). If they reach the Delta when temperatures are too warm, they may experience increased predation, physiological stress 
518 (Marine \& Cech, 2004), low dissolved oxygen (Jassby \& Van Nieuwenhuyse, 2005), synergistic impacts of toxins

519

520

521

522

523

524

525

526

527

528

529

530

531

532

533

534

535

536

537

538

539

540

541

542

543

544

545

546

547

548

549

550

551

552

553

554

555

556

557

558

559

560

561

562

563

564

565

566

567
(Dietrich et al., 2014), and other barriers to successful migration. Salmon have been shown to use differences in water temperature to optimize their growth and feeding in other estuaries (Armstrong \& Schindler, 2013). Therefore, juvenile Chinook Salmon may make use of thermal stratification as they migrate from the relatively warm Sacramento River (Figure 6a) and San Joaquin River (Figure 7a, see RRI station on the San Joaquin River) towards the cooler downstream parts of the SFE, whether it is based on season, location, or time of day (Figures 3,5). Juvenile Chinook Salmon are almost never found in the often stratified Sacramento River Ship Channel (Mahardja et al., 2021); however, they can often be routed towards the large water export facilities at the southwest end of the Delta where water can be unsuitably warm in June (Kimmerer, 2008). The unsuitably warm waters around the Delta water export facilities suggest that during warmer parts of the years, there may be high mortality rates for Chinook Salmon prior to their entrainment into the facilities (Jahn \& Kier, 2020). We found the most consistent thermal stratification in the warmer months of June-September (Supplementary Information Figures S9-S11), when few salmon are migrating through the region; however, the increase in temperatures projected under climate change may extend the period of thermal stratification earlier into the spring or later into the fall (Brown et al. 2016), making cooler depths important for early or late migrants.

In contrast to Chinook Salmon, the endangered Delta Smelt reside within SFE year-round. Delta Smelt are spawned in freshwater and largely migrate towards the low salinity zone around summertime, but parts of their population can reside in freshwater year-round in the northern portion of the Delta that includes the Sacramento River Ship Channel (Hobbs et al., 2019). Semi-anadromous Delta Smelt that migrate into the low salinity zone can experience relatively cool waters in the Suisun Bay in the summer (Figure 3); however, freshwater resident Delta Smelt have to contend with high and occasionally lethal temperatures in the north Delta (Mahardja et al., 2019; Young et al., 2020). Given the sensitivity of Delta Smelt to high temperature and the considerable amount of temperature stratification in the Sacramento River Ship Channel, it seems likely that Delta Smelt would take advantage of the cooler, deeper water at this location. However, we note that further research is needed to better understand Delta Smelt movement behavior and swimming performance relative to temperature regulation and depth. The relatively high turbidity and food density in the Sacramento River Ship Channel preferred by Delta Smelt help explain why this area hosts the last few remaining Delta Smelt populations over the past couple of years (USFWS et al., 2020). Brown et al. (2016) predicted water temperature in the Sacramento River Ship Channel under several climate change scenarios and found the region may be too warm for Delta Smelt by mid-century, however Brown et al.'s study was based on surface water temperature. If refugia are available in deeper areas of the channel as our results suggest and Delta Smelt is indeed capable of conducting vertical migration, then the Sacramento River Ship Channel may remain a refuge into the future and this suggests that recovery efforts, such as supplementation of hatchery Delta Smelt into the wild, should not exclude the Sacramento River Ship Channel as a release site.

An important caveat to our results is that the thermal limits of both species are likely to be much more dynamic than what we presented here. For example, high temperatures can reduce Delta Smelt's survival in the summer and fall (Mac Nally et al., 2010; Polansky et al., 2020), spawning timing (Brown et al., 2016), sub- and whole-organism physiology (Komoroske et al., 2015; Jeffries et al., 2016), and behavior (Davis et al., 2019b). The $25^{\circ} \mathrm{C}$ threshold we presented for Delta Smelt is likely too conservative, given that at above $20^{\circ} \mathrm{C}$, Delta Smelt behavior starts to change as they exhibit sub-lethal stress (Davis et al., 2019b) and their growth rates start to decline steeply (Lewis et al., 2021). We have concentrated on surface-depth variation in the context of providing thermal refugia for fishes. However, temperature stratification may have other implications yet to be investigated in this system. Many lakes and estuaries have found interactions between zooplankton vertical migration and the depth of the thermocline, impacting peak densities of both phytoplankton and zooplankton (Berger et al., 2010; Carstensen et al., 2015; Leach et al., 2018). Stratification may also impact rates of nutrient transport and transformation (Sharp et al., 1986; Testa \& Kemp, 2008), as well as dissolved oxygen levels (Murphy et al., 2011).

Conclusions

Our investigation confirmed previous findings that the SFE is a well-mixed estuary lacking widespread thermal stratification. However, we found that thermal stratification associated with cooler waters towards the bottom can become stronger, more consistent, and spatially extensive when overall conditions are the warmest (i.e., summer-fall period, warmer than average years, warmest time of the day). We also found that deep, terminal 
568 channels and other areas with low water velocity show more consistent thermal stratification. Given these results,

569

570

571

572

573

574

575

576

577

578

579

580

581

582

583

584

585

586

587

588

589

590

591

592

593

594

595

596

597

598

599

600

601

602

603

604

605

606

607

608

609

610 we expect that thermal stratification will become more common as temperatures continue to rise, flows shift earlier in the year, and droughts become more frequent due to climate change. Climate change is a global, intractable issue, and it remains to be seen if species of conservation concern such as Chinook Salmon and Delta Smelt in the SFE can adapt to the rapidly changing thermal landscape. Nevertheless, conservation efforts can be focused towards areas with largest potential to be refugia to provide these species with the best chance to succeed.

\section{Acknowledgments}

We dedicate this manuscript to the memory of Dr. Larry Brown, who conceived the idea for this study. We thank Michael Beakes for creating the outline map for the soap-film model, as well as Henry DeBey, Levi Lewis, Elissa Buttermore, Joshua Israel, Geoffrey Steinhart, Erwin Van Nieuwenhuyse, and Nicole Kwan for their insightful comments on earlier version of this manuscript. The findings and conclusions of this study are those of the authors and do not necessarily represent the views of their respective agencies.

\section{References}

Alfons, A., 2012. cvTools: Cross-validation tools for regression models. R package version 0.3.2., https://cran.rproject.org/package $=$ cvTools.

Armor, C., \& P. L. Herrgesell, 1985. Distribution and abundance of fishes in the San Francisco Bay estuary between 1980 and 1982. Hydrobiologia 129: 211-227.

Armstrong, J. B., \& D. E. Schindler, 2013. Going with the Flow: Spatial Distributions of Juvenile Coho Salmon Track an Annually Shifting Mosaic of Water Temperature. Ecosystems 16: 1429-1441.

Armstrong, J. B., D. E. Schindler, C. P. Ruff, G. T. Brooks, K. E. Bentley, \& C. E. Torgersen, 2013. Diel horizontal migration in streams: Juvenile fish exploit spatial heterogeneity in thermal and trophic resources. Ecology 94: 20662075 .

Auguie, B., 2017. gridExtra: Miscellaneous Functions for "Grid" Graphics. R package version 2.3. , http://cran.rproject.org/package $=$ gridExtra.

Barbier, E. B., S. D. Hacker, C. Kennedy, E. W. Koch, A. C. Stier, \& B. R. Silliman, 2011. The value of estuarine and coastal ecosystem services. Ecological Monographs 81: 169-193.

Bashevkin, S. M., 2021. Six decades (1959-2020) of water quality in the upper San Francisco Estuary: an integrated database of 11 discrete monitoring surveys in the Sacramento San Joaquin Delta, Suisun Bay, and Suisun Marsh. Environmental Data Initiative. https://doi.org/10.6073/pasta/1694ea7f9ef9cc8619b01c3588029683.

Bashevkin, S. M., \& B. Mahardja, 2021. Seasonally variable relationships between surface water temperature and inflow in the upper San Francisco Estuary. EcoEvoRxiv. https://doi.org/10.32942/osf.io/rqbdk.

Bashevkin, S. M., B. Mahardja, \& L. R. Brown, 2021. Warming in the upper San Francisco Estuary: Patterns of water temperature change from 5 decades of data. EcoEvoRxiv. https://doi.org/10.32942/osf.io/6u47y.

Berger, S. A., S. Diehl, H. Stibor, G. Trommer, \& M. Ruhenstroth, 2010. Water temperature and stratification depth independently shift cardinal events during plankton spring succession. Global Change Biology 16: 1954-1965.

Bevelhimer, M. S., \& S. M. Adams, 1993. A Bioenergetics Analysis of Diel Vertical Migration by Kokanee Salmon, Oncorhynchus nerka. Canadian Journal of Fisheries and Aquatic Sciences 50: 2336-2349.

Bever, A. J., M. L. MacWilliams, \& D. K. Fullerton, 2018. Influence of an Observed Decadal Decline in Wind Speed on Turbidity in the San Francisco Estuary. Estuaries and Coasts Estuaries and Coasts 41: 1943-1967.

Breau, C., R. A. Cunjak, \& S. J. Peake, 2011. Behaviour during elevated water temperatures: Can physiology explain movement of juvenile Atlantic salmon to cool water?. Journal of Animal Ecology 80: 844-853.

Brown, L. R., \& M. L. Bauer, 2010. Effects of hydrologic infrastructure on flow regimes of California's Central Valley rivers: Implications for fish populations. River Research and Applications 26: 751-765. 
611 Brown, L. R., W. A. Bennett, R. W. Wagner, T. Morgan-King, N. Knowles, F. Feyrer, D. H. Schoellhamer, M. T.

612

613

614

615

616

617

618

619

620

621

622

623

624

625

626

627

628

629

630

631

632

633

634

635

636

637

638

639

640

641

642

643

644

645

646

647

648

649

650

651

652

653 Stacey, \& M. Dettinger, 2013. Implications for Future Survival of Delta Smelt from Four Climate Change Scenarios for the Sacramento-San Joaquin Delta, California. Estuaries and Coasts 36: 754-774.

Brown, L. R., L. M. Komoroske, R. W. Wagner, T. Morgan-King, J. T. May, R. E. Connon, \& N. A. Fangue, 2016. Coupled Downscaled Climate Models and Ecophysiological Metrics Forecast Habitat Compression for an Endangered Estuarine Fish. PLoS ONE 11: e0146724.

Buchanan, R. A., P. L. Brandes, \& J. R. Skalski, 2018. Survival of Juvenile Fall-Run Chinook Salmon through the San Joaquin River Delta, California, 2010-2015. North American Journal of Fisheries Management 38: 663-679.

Carstensen, J., R. Klais, \& J. E. Cloern, 2015. Phytoplankton blooms in estuarine and coastal waters: Seasonal patterns and key species. Estuarine, Coastal and Shelf Science 162: 98-109.

Cloern, J. E., A. D. Jassby, T. S. Schraga, E. Nejad, \& C. Martin, 2017. Ecosystem variability along the estuarine salinity gradient: Examples from long-term study of San Francisco Bay. Limnology and Oceanography 62: S272S291.

Comte, L., \& G. Grenouillet, 2013. Do stream fish track climate change? Assessing distribution shifts in recent decades. Ecography 36: 1236-1246.

Davis, B. E., D. E. Cocherell, T. Sommer, R. D. Baxter, T.-C. Hung, A. E. Todgham, \& N. A. Fangue, 2019a. Sensitivities of an endemic, endangered California smelt and two non-native fishes to serial increases in temperature and salinity: implications for shifting community structure with climate change. Conservation Physiology 7: coy076.

Davis, B. E., M. J. Hansen, D. E. Cocherell, T. X. Nguyen, T. Sommer, R. D. Baxter, N. A. Fangue, \& A. E. Todgham, 2019b. Consequences of temperature and temperature variability on swimming activity, group structure, and predation of endangered delta smelt. Freshwater Biology 64: 2156-2175.

Dettinger, M. D., \& D. R. Cayan, 1995. Large-Scale Atmospheric Forcing of Recent Trends Toward Early Snowmelt Runoff in California. Journal of Climate 8: 606-623.

Dettinger, M. D., D. R. Cayan, H. F. Diaz, \& D. M. Meko, 1998. North-South precipitation patterns in western North America on interannual-to-decadal timescales. Journal of Climate 11: 3095-3111.

Dietrich, J. P., A. L. Van Gaest, S. A. Strickland, \& M. R. Arkoosh, 2014. The impact of temperature stress and pesticide exposure on mortality and disease susceptibility of endangered Pacific salmon. Chemosphere 108: $353-$ 359, https://doi.org/10.1016/j.chemosphere.2014.01.079.

Goertler, P., B. Mahardja, \& T. Sommer, 2021. Striped bass (Morone saxatilis) migration timing driven by estuary outflow and sea surface temperature in the San Francisco Bay-Delta, California. Scientific Reports Nature Publishing Group UK 11: 1510, https://doi.org/10.1038/s41598-020-80517-5.

Gräler, B., E. Pebesma, \& G. Heuvelink, 2016. Spatio-temporal interpolation using gstat. R Journal 8: 204-218.

Gross, E., S. Andrews, B. Bergamaschi, B. Downing, R. Holleman, S. Burdick, \& J. Durand, 2019. The use of Stable Isotope-Based water age to evaluate a hydrodynamic model. Water 11:.

Hamilton, D. P., T. Chan, M. S. Robb, C. B. Pattiaratchi, \& M. Herzfeld, 2001. The hydrology of the upper Swan River Estuary with focus on an artificial destratification trial. Hydrological Processes 15: 2465-2480.

Hickling, R., D. B. Roy, J. K. Hill, R. Fox, \& C. D. Thomas, 2006. The distributions of a wide range of taxonomic groups are expanding polewards. Global Change Biology 12: 450-455.

Hobbs, J. A., L. S. Lewis, M. Willmes, C. Denney, \& E. Bush, 2019. Complex life histories discovered in a critically endangered fish. Scientific Reports 9: 16772.

Hobbs, J., P. B. Moyle, N. Fangue, \& R. E. Connon, 2017. Is Extinction Inevitable for Delta Smelt and Longfin Smelt? An Opinion and Recommendations for Recovery. San Francisco Estuary and Watershed Science 15, http://escholarship.org/uc/item/2k06n13x. 
654 ICF International, 2010. Stockton Deep Water Ship Channel Demonstration Dissolved Oxygen Aeration Facility 655 Project. Sacramento, CA.

656 Interagency Ecological Program (IEP), M. Martinez, \& S. Perry, 2021. Interagency Ecological Program: Discrete

657

658

659

660

661

662

663

664

665

666

667

668

669

670

671

672

673

674

675

676

677

678

679

680

681

682

683

684

685

686

687

688

689

690

691

692

693

694

695

696

697

698 water quality monitoring in the Sacramento-San Joaquin Bay-Delta, collected by the Environmental Monitoring Program, 1975-2020. Environmental Data Initiative, https://doi.org/10.6073/pasta/31f724011cae3d51b2c31c6d144b60b0.

Interagency Ecological Program (IEP), C. Pien, J. Hamilton, R. Hartman, M. Nelson, J. Saraceno, B. M. Schreier, \& B. Davis, 2020. Hourly water temperature from the San Francisco Estuary, 1986 - 2019 ver 2. Environmental Data Initiative, https://doi.org/10.6073/pasta/7385985f68b02c0deb2a9e425a9f3ad8.

Jahn, A., \& W. Kier, 2020. Reconsidering the estimation of salmon mortality caused by the state and federal water export facilities in the Sacramento-San Joaquin Delta, San Francisco Estuary. San Francisco Estuary and Watershed Science 18, https://escholarship.org/uc/item/0jc956v6.

Jassby, A. D., \& E. E. Van Nieuwenhuyse, 2005. Low Dissolved Oxygen in an Estuarine Channel (San Joaquin River, California): Mechanisms and Models Based on Long-Term Time Series. San Francisco Estuary and Watershed Science 3, https://escholarship.org/uc/item/0tb0f19p.

Jeffries, K. M., R. E. Connon, B. E. Davis, L. M. Komoroske, M. T. Britton, T. Sommer, A. E. Todgham, \& N. A. Fangue, 2016. Effects of high temperatures on threatened estuarine fishes during periods of extreme drought. Journal of Experimental Biology 219: 1705-1716.

Jobling, M., 1997. Temperature and growth: modulation of growth rate via temperature change In Wood, C. M., \& D. G. McDonald (eds), Global Warming Implications for Freshwater and Marine Fish. Cambridge University Press: $225-254$.

Kassambara, A., 2020. ggpubr: "ggplot2” Based Publication Ready Plots. R package version 0.4.0, https:/cran.rproject.org/package $=$ ggpubr.

Keppel, G., K. P. Van Niel, G. W. Wardell-Johnson, C. J. Yates, M. Byrne, L. Mucina, A. G. T. Schut, S. D.

Hopper, \& S. E. Franklin, 2012. Refugia: Identifying and understanding safe havens for biodiversity under climate change. Global Ecology and Biogeography 21: 393-404.

Kimmerer, W., 2004. Open Water Processes of the San Francisco Estuary: From Physical Forcing to Biological Responses. San Francisco Estuary and Watershed Science 2, https://escholarship.org/uc/item/9bp499mv.

Kimmerer, W., 2008. Losses of Sacramento River Chinook Salmon and Delta Smelt to Entrainment in Water Diversions in the Sacramento-San Joaquin Delta. San Francisco Estuary and Watershed Science 6, https://doi.org/10.15447/sfews.2008v6iss2art2.

Komoroske, L. M., R. E. Connon, K. M. Jeffries, \& N. A. Fangue, 2015. Linking transcriptional responses to organismal tolerance reveals mechanisms of thermal sensitivity in a mesothermal endangered fish. Molecular Ecology 24: 4960-4981.

Leach, T. H., B. E. Beisner, C. C. Carey, P. Pernica, K. C. Rose, Y. Huot, J. A. Brentrup, I. Domaizon, H. P. Grossart, B. W. Ibelings, S. Jacquet, P. T. Kelly, J. A. Rusak, J. D. Stockwell, D. Straile, \& P. Verburg, 2018. Patterns and drivers of deep chlorophyll maxima structure in 100 lakes: The relative importance of light and thermal stratification. Limnology and Oceanography 63: 628-646.

Lenoch, L. E. K., P. R. Stumpner, J. R. Burau, L. C. Loken, \& S. Sadro, 2021. Dispersion and Stratification Dynamics in the Upper Sacramento Deep Water Ship Channel. San Francisco Estuary and Watershed Science In Press.

Lewis, L., C. Denney, M. Willmes, W. Xieu, R. Fichman, F. Zhao, B. Hammock, A. Schultz, N. Fangue, \& J. Hobbs, 2021. Otolith-based approaches indicate strong effects of environmental variation on growth of a Critically Endangered estuarine fish. Marine Ecology Progress Series Inter-Research Science Center 676: 37-56, http://dx.doi.org/10.3354/meps13848. 
Lotze, H. K., H. S. Lenihan, B. J. Bourque, R. H. Bradbury, R. G. Cooke, M. C. Kay, S. M. Kidwell, M. X. Kirby, C. H. Peterson, \& J. B. C. Jackson, 2006. Depletion degradation, and recovery potential of estuaries and coastal seas. Science 312: 1806-1809.

Mac Nally, R., J. R. Thomson, W. J. Kimmerer, F. Feyrer, K. B. Newman, A. Sih, W. A. Bennett, L. Brown, E. Fleishman, S. D. Culberson, \& G. Castillo, 2010. Analysis of pelagic species decline in the upper San Francisco Estuary using multivariate autoregressive modeling (MAR). Ecological Applications 20: 1417-1430.

Mahardja, B., J. A. Hobbs, N. Ikemiyagi, A. Benjamin, \& A. J. Finger, 2019. Role of freshwater floodplain-tidal slough complex in the persistence of the endangered delta smelt. PLoS ONE 14: 1-20.

Mahardja, B., L. Mitchell, M. Beakes, C. Johnston, C. Graham, P. Goertler, D. Barnard, G. Castillo, \& B. Matthias, 2021. Leveraging Delta Smelt Monitoring for Detecting Juvenile Chinook Salmon in the San Francisco Estuary. San Francisco Estuary and Watershed Science 19, https://escholarship.org/uc/item/9sp7r7q4.

Marine, K. R., \& J. J. Cech, 2004. Effects of high water temperature on growth, smoltification, and predator avoidance in juvenile Sacramento River Chinook Salmon. North American Journal of Fisheries Management 24: $198-210$.

Michel, C. J., J. M. Smith, B. M. Lehman, N. J. Demetras, D. D. Huff, P. L. Brandes, J. A. Israel, T. P. Quinn, \& S. A. Hayes, 2020. Limitations of Active Removal to Manage Predatory Fish Populations. North American Journal of Fisheries Management 40: 3-16.

Monismith, S. G., J. L. Hench, D. A. Fong, N. J. Nidzieko, W. E. Fleenor, L. P. Doyle, \& S. G. Schladow, 2009. Thermal variability in a tidal river. Estuaries and Coasts $32: 100-110$.

Moyle, P. B., L. R. Brown, J. R. Durand, \& J. A. Hobbs, 2016. Delta Smelt: Life History and Decline of a OnceAbundant Species in the San Francisco Estuary. San Francisco Estuary and Watershed Science 14, https://escholarship.org/uc/item/09k9f76s.

Moyle, P. B., J. A. Hobbs, \& J. R. Durand, 2018. Delta Smelt and Water Politics in California. Fisheries 43: 42-50.

Munsch, S. H., C. M. Greene, R. C. Johnson, W. H. Satterthwaite, H. Imaki, \& P. L. Brandes, 2019. Warm, dry winters truncate timing and size distribution of seaward-migrating salmon across a large, regulated watershed. Ecological Applications 29: e01880.

Murphy, R. R., W. M. Kemp, \& W. P. Ball, 2011. Long-Term Trends in Chesapeake Bay Seasonal Hypoxia, Stratification, and Nutrient Loading. Estuaries and Coasts 34: 1293-1309.

Myrick, C. A., \& J. J. Cech, 2004. Temperature effects on juvenile anadromous salmonids in California's central valley: What don't we know? Reviews in Fish Biology and Fisheries 14: 113-123.

National Marine Fisheries Service (NMFS), 2019. Biological Opinion on Long-term Operation of the Central Valley Project and the State Water Project. National Oceanic and Atmospheric Administration.

Neverman, D., \& W. A. Wurtsbaugh, 1994. The thermoregulatory function of diel vertical migration for a juvenile fish, Cottus extensus. Oecologia 98: 247-256.

Nichols, F. H., J. E. Cloern, S. N. Luoma, \& D. H. Peterson, 1986. The Modification of an Estuary. Science 231: 567-573.

Nobriga, M. L., C. J. Michel, R. C. Johnson, \& J. D. Wikert, 2021. Coldwater fish in a warm water world: Implications for predation of salmon smolts during estuary transit. Ecology and Evolution .

Nobriga, M. L., T. R. Sommer, F. Feyrer, \& K. Fleming, 2008. Long-Term Trends in Summertime Habitat Suitability for Delta Smelt, Hypomesus transpacificus. San Francisco Estuary and Watershed Science 6, https://escholarship.org/uc/item/5xd3q8tx.

Pebesma, E., 2018. Simple features for R: Standardized support for spatial vector data. R Journal 10: 439-446.

Pebesma, E. J., 2004. Multivariable geostatistics in S: The gstat package. Computers and Geosciences 30: 683-691. 
742 Perry, R. W., R. A. Buchanan, P. L. Brandes, J. R. Burau, \& J. A. Israel, 2016. Anadromous Salmonids in the Delta:

743

744

745

746

747

748

749

750

751

752

753

754

755

756

757

758

759

760

761

762

763

764

765

766

767

768

769

770

771

772

773

774

775

776

777

778

779

780

781

782

783

784

New Science 2006-2016. San Francisco Estuary and Watershed Science 14:

Polansky, L., K. B. Newman, \& L. Mitchell, 2020. Improving inference for nonlinear state-space models of animal population dynamics given biased sequential life stage data. Biometrics 77: 352-361.

R Core Team, 2021. R: A language and environment for statistical computing. R foundation for Statistical Computing. Vienna, https://www.r-project.org/.

Ray, G. C., 2005. Connectivities of estuarine fishes to the coastal realm. Estuarine, Coastal and Shelf Science 64: $18-32$.

Resources Management Associates (RMA), 2021. Numerical Modeling in Support of Reclamation Delta Smelt Summer/Fall Habitat Analysis. Report prepared for United States Bureau of Reclamation.

Rose, K. A., W. J. Kimmerer, K. P. Edwards, \& W. A. Bennett, 2013. Individual-based modeling of delta smelt population dynamics in the upper san francisco estuary: II. alternative baselines and good versus bad years. Transactions of the American Fisheries Society 142: 1260-1272.

Schraga, T. S., \& J. E. Cloern, 2017. Water quality measurements in San Francisco Bay by the U.S. Geological Survey, 1969-2015. Scientific Data 4: 1-14.

Scully, M. E., C. Friedrichs, \& J. Brubaker, 2005. Control of Estuarine Stratification and Mixing by Wind-induced of the Estuarine Density Field. Estuaries 28: 321-326.

Sharp, J. H., L. A. Cifuentes, R. B. Coffin, J. R. Pennock, \& K. C. Wong, 1986. The influence of river variability on the circulation, chemistry, and microbiology of the Delaware Estuary. Estuaries 9: 261-269.

Simpson, J. H., J. Brown, J. Matthews, \& G. Allen, 1990. Tidal straining, density currents, and stirring in the control of estuarine stratification. Estuaries 13: 125-132.

Sommer, T., \& F. Mejia, 2013. A Place to Call Home: A Synthesis of Delta Smelt Habitat in the Upper San Francisco Estuary. San Francisco Estuary and Watershed Science 11, https://escholarship.org/uc/item/32c8t244.

Stevens, D. E., \& L. W. Miller, 1983. Effects of River Flow on Abundance of Young Chinook Salmon, American Shad, Longfin Smelt, and Delta Smelt in the Sacramento-San Joaquin River System. North American Journal of Fisheries Management 3: 425-437.

Strange, J. S., 2013. Factors influencing the behavior and duration of residence of adult Chinook salmon in a stratified estuary. Environmental Biology of Fishes 96: 225-243.

Swanson, C., T. Reid, P. S. Young, \& J. J. Cech, 2000. Comparative environmental tolerances of threatened delta smelt (Hypomesus transpacificus) and introduced wakasagi (H. nipponensis) in an altered California estuary. Oecologia 123: 384-390.

Testa, J. M., \& W. M. Kemp, 2008. Variability of biogeochemical processes and physical transport in a partially stratified estuary: A box-modeling analysis. Marine Ecology Progress Series 356: 63-79.

Torgersen, C. E., D. M. Price, H. W. Li, \& B. A. McIntosh, 1999. Multiscale thermal refugia and stream habitat associations of chinook salmon in northeastern Oregon. Ecological Applications 9: 301-319.

Turner, J. L., \& H. K. Chadwick, 1972. Distribution and Abundance of Young-of-the-Year Striped Sacramento . San Joaquin Estuary. Transactions of the American Fisheries Society 3: 442-452.

United States Fish and Wildlife Service (USFWS), C. Johnston, S. Durkacz, R. McKenzie, J. Speegle, B. Mahardja, B. Perales, D. Bridgman, \& K. Erly, 2020. Interagency Ecological Program and US Fish and Wildlife Service: San Francisco Estuary Enhanced Delta Smelt Monitoring Program data, 2016-2020 ver 3. Environmental Data Initiative. https://doi.org/10.6073/pasta/764f27ff6b0a7b11a487a71c90397084.

Vroom, J., M. van der Wegen, R. C. Martyr-Koller, \& L. V. Lucas, 2017. What Determines Water Temperature Dynamics in the San Francisco Bay-Delta System?. Water Resources Research 53: 9901-9921. 
Wagner, R. W., M. Stacey, L. R. Brown, \& M. Dettinger, 2011. Statistical Models of Temperature in the Sacramento-San Joaquin Delta Under Climate-Change Scenarios and Ecological Implications. Estuaries and Coasts 34: 544-556.

Weinke, A. D., \& B. A. Biddanda, 2019. Influence of episodic wind events on thermal stratification and bottom water hypoxia in a Great Lakes estuary. Journal of Great Lakes Research International Association for Great Lakes Research 45: 1103-1112, https://doi.org/10.1016/j.jglr.2019.09.025.

Whipple, A., R. Grossinger, D. Rankin, B. Stanford, \& R. Askevold, 2012. Sacramento-San Joaquin Delta historical ecology investigation: exploring pattern and process. San Francisco Estuary Institute, Richmond, https://www.sfei.org/documents/sacramento-san-joaquin-delta-historical-ecology-investigation-exploring-patternand-proces.

Wickham, H., 2016. ggplot2: Elegant Graphics for Data Analysis. Springer-Verlag New York.

Wood, S. N., 2011. Fast stable restricted maximum likelihood and marginal likelihood estimation of semiparametric generalized linear models. Journal of the Royal Statistical Society. Series B: Statistical Methodology 73: 3-36.

Wood, S. N., M. V. Bravington, \& S. L. Hedley, 2008. Soap film smoothing. Journal of the Royal Statistical Society. Series B: Statistical Methodology 70: 931-955.

Xu, J., W. Long, J. D. Wiggert, L. W. J. Lanerolle, C. W. Brown, R. Murtugudde, \& R. R. Hood, 2012. Climate Forcing and Salinity Variability in Chesapeake Bay, USA. Estuaries and Coasts 35: 237-261.

Young, M. J., F. Feyrer, P. R. Stumpner, V. Larwood, O. Patton, \& L. R. Brown, 2020. Hydrodynamics drive pelagic communities and food web structure in a tidal environment. International Review of Hydrobiology 1-17.

\section{Funding:}

No specific funds, grants, or other support were received during the preparation of this manuscript.

\section{Competing Interests:}

The authors have no relevant financial or non-financial interests to disclose.

\section{Author Contributions:}

All authors contributed to the study conception and design. Data preparation and analysis were performed by Brian Mahardja, Samuel Bashevkin, Catarina Pien, and Michelle Nelson. All authors contributed to writing, reviewing, and editing the manuscript. All authors have read and approved the final manuscript.

\section{Data Availability:}

The discrete temperature dataset used in the study can be found in the following posting:

Bashevkin, S. M., 2021. Six decades (1959-2020) of water quality in the upper San Francisco Estuary: an integrated database of 11 discrete monitoring surveys in the Sacramento San Joaquin Delta, Suisun Bay, and Suisun Marsh. Environmental Data Initiative. https://doi.org/10.6073/pasta/1694ea7f9ef9cc8619b01c3588029683.

Surface temperature data from the continuous monitoring stations used in the study can be found in the following posting:

Interagency Ecological Program (IEP), C. Pien, J. Hamilton, R. Hartman, M. Nelson, J. Saraceno, B. M. Schreier, \& B. Davis, 2020. Hourly water temperature from the San Francisco Estuary, 1986 - 2019 ver 2. Environmental Data Initiative, https://doi.org/10.6073/pasta/7385985f68b02c0deb2a9e425a9f3ad8. 
824 Bottom temperature data are available upon request and will be posted upon publication on the Environmental Data 825 Initiative website. 